\title{
The transcription levels and prognostic values of seven proteasome alpha subunits in human cancers
}

\author{
Yunhai Li ${ }^{1,2}$, Jing Huang ${ }^{1}$, Jiazheng Sun ${ }^{1}$, Shili Xiang ${ }^{1}$, Dejuan Yang ${ }^{1,2}$, Xuedong \\ Ying $^{1,2}$, Mengqi Lu1 ${ }^{1}$, Hongzhong Li ${ }^{1,2}$, Guosheng Ren ${ }^{1,2}$ \\ ${ }^{1}$ Chongqing Key Laboratory of Molecular Oncology and Epigenetics, The First Affiliated Hospital of Chongqing Medical \\ University, Chongqing, China \\ ${ }^{2}$ Department of Endocrine and Breast Surgery, The First Affiliated Hospital of Chongqing Medical University, Chongqing, \\ China
}

Correspondence to: Hongzhong Li, email: tibetlhz@126.com

Guosheng Ren, email: rengs726@126.com

Keywords: proteasome alpha subunits, cancer, oncomine, TCGA, Kaplan-Meier plotter

Received: June 19, $2016 \quad$ Accepted: December 01, $2016 \quad$ Published: December 10, 2016

\section{ABSTRACT}

Proteasome alpha subunits (PSMAs) have been shown to participate in the malignant progression of human cancers. However, the expression patterns and prognostic values of individual PSMAs remain elusive in most cancers. In the present study, we investigated the mRNA expression levels of seven PSMAs in different kinds of cancers using Oncomine and The Cancer Genome Atlas (TCGA) databases. The prognostic significance of PSMAs was also determined by Kaplan-Meier Plotter and PrognScan databases. Combined with Oncomine and TCGA, the mRNA expression levels of PSMA1-7 were significantly upregulated in breast, lung, gastric, bladder and head and neck cancer compared with normal tissues. Moreover, only PSMA6 and PSMA5 were not overexpressed in colorectal and kidney cancer, respectively. In survival analyses based on Kaplan-Meier Plotter, PSMA1-7 showed significant prognostic values in breast, lung and gastric cancer. Furthermore, potential correlations between PSMAs and survival outcomes were also observed in ovarian cancer, colorectal cancer and melanoma by Kaplan-Meier Plotter and PrognScan. These data indicated that PSMAs might serve as novel biomarkers and potential therapeutic targets for multiple human cancers. However, further studies are needed to explore the detailed biological functions and molecular mechanisms involved in tumor progression.

\section{INTRODUCTION}

Cancer, as a global health problem, accounts for the leading cause of death in most countries and regions, but remains a major challenge in current medicine [1]. In 2016, a total of 1,685,210 new cancer cases and 595,690 cancer deaths are predicted to occur in the United States [2]. Despite improved diagnostics, advanced surgical methods and growing numbers of anti-cancer drugs and targeted therapies, cancer is still a major limitation of patients' life quality and a severe social and economical burden. It is thus imperative to investigate the underlying mechanisms of cancer initiation and progression, as well as to identify potential biomarkers for improving diagnosis, therapy and prognosis.

The 26S proteasome, consisting of 20S proteasome core and 19S regulatory particles, is a multi-subunit complex playing a central role in degrading obsolete and impaired endogenous proteins [3]. Emerging evidence has indicated that multiple subunits of proteasome were strongly implicated in regulating the biological progression of cancer cells such as proliferation, apoptosis, cell cycle, DNA repair, invasion and metastasis [4-7]. Aberration and abnormal expression of proteasome subunits have been demonstrated in many tumors including breast cancer [8], lung cancer [5, 7], hepatocellular carcinoma [9] and colorectal cancer [10]. For instance, PSMB4, a subunit of the 20S core complex, has been shown to be upregulated in epithelial ovarian cancer, and overexpression of PSMB4 was significantly related to clinicopathological characteristics and worse prognosis in epithelial ovarian cancer patients [11]. Another well studied oncoprotein PSMD10 is frequently overexpressed in hepatocellular carcinoma (HCC) and regulates the balance between apoptosis and cell cycle via the degradation of RB1 and TP53 [12, 13]. Overexpression of PSMD10 promotes 
HCC invasiveness and metastasis, and could serve as a valuable biomarker for recurrence and survival [9].

Proteasome alpha subunits (PSMAs) are major components of the $20 \mathrm{~S}$ proteasome core complex. Two rings formed by alpha subunits are necessary for proteasome assembly and the binding of the $19 \mathrm{~S}$ or $11 \mathrm{~S}$ regulatory complex [14]. There are seven unique alpha subunits, PSMA1-7, of which several have been demonstrated to be closely associated with cancers. A previous study reported that the mRNA expression of PSMA1 and PSMA5 were significantly increased in pulmonary neuroendocrine tumors compared to normal tissues [5]. Polymorphisms in PSMA4 contribute to lung cancer susceptibility, and upregulated PSMA4 in lung cancer plays an important role in regulating cell proliferation and apoptosis $[15,16]$. PSMA7 participates in the degradation of multiple proteins that are necessary for the replication of hepatitis B virus, which is closely related to the development of $\mathrm{HCC}[17,18]$. In addition, the expression of PSMA7 has been shown to be overexpressed in colorectal cancer and was significantly associated with prognosis in cancer patients [19]. Depletion of PSMA7 in colorectal cancer cells had an inhibition effect on cell invasion and migration [4]. These preliminary studies suggest that PSMAs are involved in multiple human cancers, but a comprehensive analysis of the seven genes, which might act as potential therapeutic targets or prognostic biomarkers, is still absent.

In the present study, we investigated the mRNA expression differences between tumor and normal tissues in multiple cancers for PSMA1-7 using Oncomine and TCGA databases. Additionally, the prognostic significance of these PSMAs was also determined via Kaplan-Meier Plotter (KM Plotter) and PrognScan databases.

\section{RESULTS}

\section{The mRNA expression patterns of PSMAs in human cancers}

Oncomine was used to investigate the mRNA expression differences of the seven PSMAs between tumor and normal tissues in multiple cancers. As shown in Figure 1, the database contained a total of 353, 357, 353, 346, 355, 353 and 309 unique analyses for PSMA1, PSMA2, PSMA3, PSMA4, PSMA5, PSMA6 and PSMA7, respectively. There were 11 studies showing a significant statistical difference for PSMA1, of which 10 showed that mRNA expression level of PSMA1 was increased in tumor than normal tissues in seven kinds of cancers, while one regarding brain and CNS cancer showed an opposite result. As for PSMA2, all 24 datasets with statistical significance revealed higher expression levels of PSMA2 in cancer tissues than in normal tissues. 18 analyses showed increased expression of PSMA3 in tumors, while two showed a significantly decreased expression level in brain and CNS cancer. Compared with normal tissues, PSMA4 was expressed at a much higher level in tumors, demonstrated by 36 analyses involving nine kinds of carcinomas, but six studies showed a reduced expression level of PSMA4 in breast cancer, leukemia, lymphoma and two other cancers. PSMA5 was shown to be upregulated in nine types of cancers by 25 studies and downregulated in breast cancer and myeloma by two analyses. Overexpression of PSMA6 and PSMA7 was found in tumors compared with normal tissues based on 29 and 32 studies, respectively. Meanwhile, only four studies for PSMA6 and two for PSMA7 showed that the mRNA expression level in tumors was lower than in normal samples. Together, among all the datasets with significantly statistical differences, most revealed higher transcription levels of the seven genes in tumors than in normal tissues.

\section{Transcription levels and prognostic significance of PSMAs in breast cancer}

We first analyzed the mRNA expression level of PSMAs in breast cancer in Oncomine database via cancer vs. normal analysis. There were a total of 13 datasets comparing the mRNA expression level differences between tumors and normal tissues in breast cancer. Among the 13 datasets, all of them were available for PSMA1-3 and PSMA5-6, while only 10 datasets for PSMA4 and nine for PSMA7. For both PSMA1 and PSMA2, no datasets revealed significant difference between the breast cancer group and normal tissue group (Figure 1). PSMA3 was found to be significantly elevated in invasive lobular breast carcinoma compared with normal tissues in Radvanyi's dataset [20]. PSMA4 was upregulated in invasive ductal breast carcinoma and lobular breast carcinoma in datasets from Zhao [21] and Radvanyi [20], while it was downregulated in invasive breast cancer compared with normal breast tissues in Finak's dataset [22]. In a group of datasets including Perou [23], Curtis [24], Sorlie [25], Sorlie 2 [26], Radvanyi, and Zhao [21], the mRNA level of PSMA5 was significantly overexpressed in cancer tissues. However, Finak's dataset [22] showed an opposite result for PSMA5. According to Perou's dataset [23] and two analyses of Sorlie [25], PSMA6 was markedly elevated in ductal breast carcinoma compared to normal tissues. The mRNA level of PSMA7 was higher in breast cancer than in normal samples in Richardson's datasets 2 [27], but was lower in Finak's study [22]. All of the results with statistical significance are summarized in Table 1. Then, the mRNA HiSeq expression data of TCGA was utilized to further determine the expression of the seven PSMAs in breast cancer. As shown in Figure 2, all of the seven genes were significantly overexpressed in 1095 cases of breast cancer compared with 113 normal samples.

Subsequently, the prognostic effects of PSMAs were determined in KM Plotter database (www.kmplot.com). 
The desired probe IDs for each gene are shown in Supplementary Table S1. The results showed that high expression of PSMA1 $(\mathrm{HR}=1.48 ; 95 \% \mathrm{CI}: 1.32-1.67 ; p<$ $0.001)$, PSMA2 ( HR = 1.14; 95\% CI: $1.02-1.28 ; p=0.021)$, PSMA3 (HR $=1.34,95 \%$ CI: $1.19-1.50 ; p<0.001)$, PSMA4 $(\mathrm{HR}=1.53 ; 95 \% \mathrm{CI}: 1.36-1.71 ; p<0.001)$, PSMA5 (HR $=$ 0.71; 95\% CI: 0.60-0.84; $p<0.001)$, PSMA6 (HR = 1.39; 95\% CI: $1.24-1.56 ; p<0.001)$ and PSMA7 (HR $=1.50 ; 95 \%$ CI: $1.33-1.68 ; p<0.001)$ were all significantly associated with relapse free survival (RFS) (Table 2). Increased mRNA levels of PSMA5 and PSMA7 were also related to overall survival $(\mathrm{OS})$ with $\mathrm{HR}=0.58(0.41-0.83), p=0.003$ and $\mathrm{HR}=1.52$ (1.20-1.93), $p<0.001$, respectively, and distant metastasis free survival (DMFS) with $\mathrm{HR}=0.61(0.44-0.85)$, $p=0.003$ and $\mathrm{HR}=1.32(1.08-1.62), p=0.007$, respectively, but not post progression survival (PPS) (Table 2). In recent years, four intrinsic biological subtypes of breast cancer including luminal A, luminal B, HER2-enriched and basallike have been revealed by comprehensive transcriptional profiling studies and have been shown to be robust for

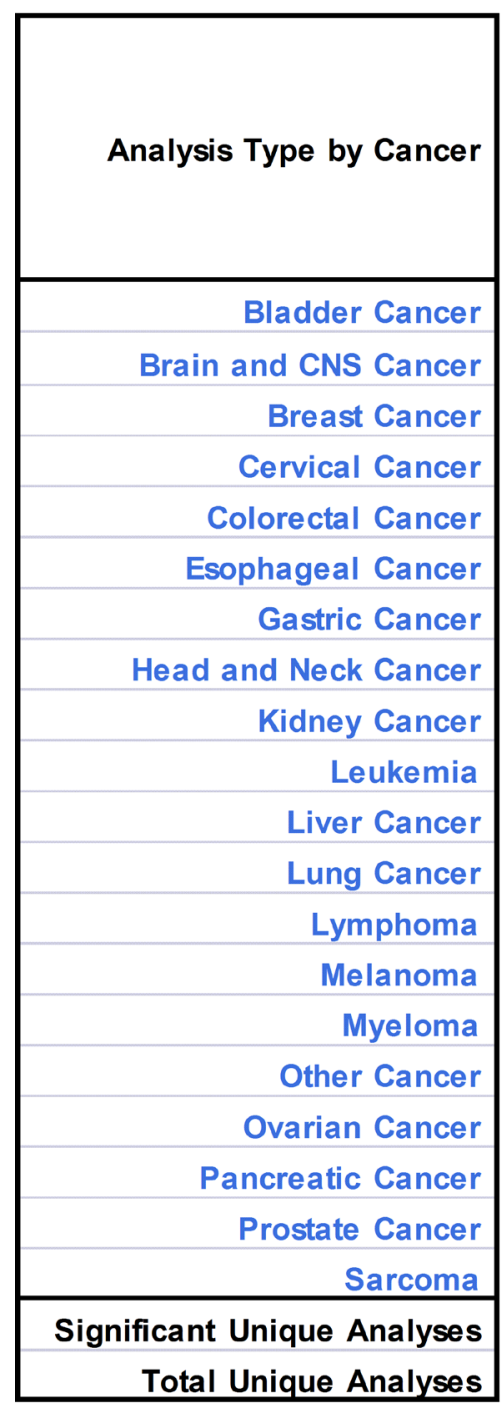

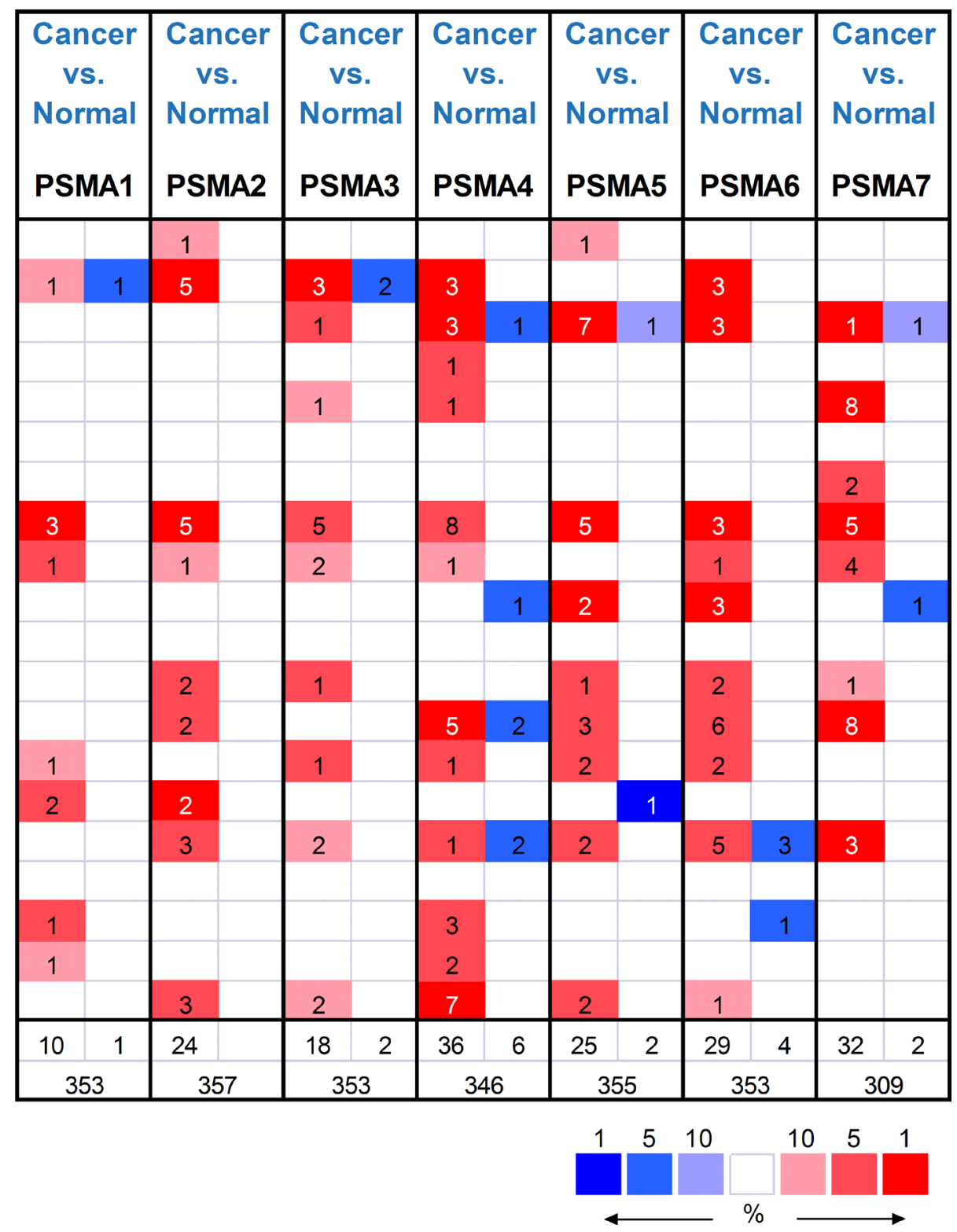

Figure 1: The mRNA expression patterns of PSMAs in overall cancers. The mRNA expression difference between tumors and normal tissues were analyzed in Oncomine database with thresholds as follows: $p$-value: 0.01 ; fold change: 2 ; gene rank: $10 \%$; data type: mRNA. The number in the colored cell represents the number of analyses meeting these thresholds. The color depth was determined by the gene rank. The red cells indicate that the mRNA levels of target genes are higher in tumor tissues than in normal tissues, while blue cells indicate that the mRNA levels of target genes are lower in tumor tissues than in normal tissues. 
Table 1: Analyses of PSMAs in breast cancer

\begin{tabular}{|c|c|c|c|c|c|c|}
\hline Gene & Dataset & $\begin{array}{l}\text { Normal } \\
\text { (Cases) }\end{array}$ & Tumor (Cases) & $\begin{array}{c}\text { Fold } \\
\text { change }\end{array}$ & $t$-Test & $p$-value \\
\hline PSMA3 & Radvanyi Breast & Breast (6) & Invasive Lobular Breast Carcinoma (5) & 2.722 & 3.308 & $7.00 \mathrm{E}-03$ \\
\hline \multirow[t]{4}{*}{ PSMA4 } & Zhao Breast & Breast (3) & Invasive Ductal Breast Carcinoma(38) & 2.326 & 10.982 & $6.36 \mathrm{E}-13$ \\
\hline & & Breast (3) & Lobular Breast Carcinoma (19) & 2.283 & 8.226 & $3.87 \mathrm{E}-08$ \\
\hline & Radvanyi Breast & Breast (8) & Invasive Ductal Breast Carcinoma(30) & 2.317 & 3.597 & $3.00 \mathrm{E}-03$ \\
\hline & Finak Breast & Breast (6) & Invasive Breast Carcinoma (53) & -15.502 & -22.062 & $2.74 \mathrm{E}-29$ \\
\hline \multirow[t]{8}{*}{ PSMA5 } & Perou Breast & Breast (3) & Ductal Breast Carcinoma(36) & 2.237 & 14.385 & $3.58 \mathrm{E}-16$ \\
\hline & Curtis Breast & Breast (114) & Ductal Breast Carcinoma in Situ (10) & 2.023 & 7.295 & $1.72 \mathrm{E}-05$ \\
\hline & & Breast (114) & Medullary Breast Carcinoma (32) & 2.016 & 9.981 & $5.41 \mathrm{E}-12$ \\
\hline & Sorlie Breast & Breast (4) & Ductal Breast Carcinoma(65) & 2.031 & 6.165 & $1.00 \mathrm{E}-03$ \\
\hline & Sorlie Breast 2 & Breast (4) & Ductal Breast Carcinoma(89) & 2.051 & 7.514 & $8.58 \mathrm{E}-04$ \\
\hline & Radvanyi Breast & Breast (9) & Invasive Mixed Breast Carcinoma (3) & 2.174 & 2.879 & $9.00 \mathrm{E}-03$ \\
\hline & Zhao Breast & Breast (3) & Lobular Breast Carcinoma (21) & 2.454 & 8.240 & $2.23 \mathrm{E}-04$ \\
\hline & Finak Breast & Breast (6) & Invasive Breast Carcinoma (53) & -6.410 & -17.907 & $7.88 \mathrm{E}-20$ \\
\hline \multirow[t]{3}{*}{ PSMA6 } & Perou Breast & Breast (3) & Ductal Breast Carcinoma(36) & 2.287 & 13.654 & $4.65 \mathrm{E}-16$ \\
\hline & Sorlie Breast & Breast (4) & Ductal Breast Carcinoma(65) & 2.094 & 7.702 & $2.55 \mathrm{E}-04$ \\
\hline & Sorlie Breast 2 & Breast (4) & Ductal Breast Carcinoma(92) & 2.070 & 8.936 & $2.38 \mathrm{E}-04$ \\
\hline \multirow[t]{2}{*}{ PSMA7 } & $\begin{array}{l}\text { Richardson } \\
\text { Breast } 2\end{array}$ & Breast (7) & Ductal Breast Carcinoma(40) & 2.585 & 11.321 & $1.61 \mathrm{E}-12$ \\
\hline & Finak Breast & Breast (6) & Invasive Breast Carcinoma (53) & -13.894 & -17.859 & $8.57 \mathrm{E}-21$ \\
\hline
\end{tabular}

predicting treatment sensitivity and survival outcomes $[23,28]$. Therefore, subgroup analyses based on these four intrinsic subtypes were carried out. Intriguingly, upregulated PSMA1-4 and PSMA6-7 were all significantly associated with worse RFS in the luminal A and B groups, but not in the basal-like or HER2-enriched group. In addition, high expression of PSMA5 was associated with better prognosis in patients with the luminal A or basal-like types, which was consistent with the overall cohort. The results of the subgroup analyses are summarized in Supplementary Table S2.

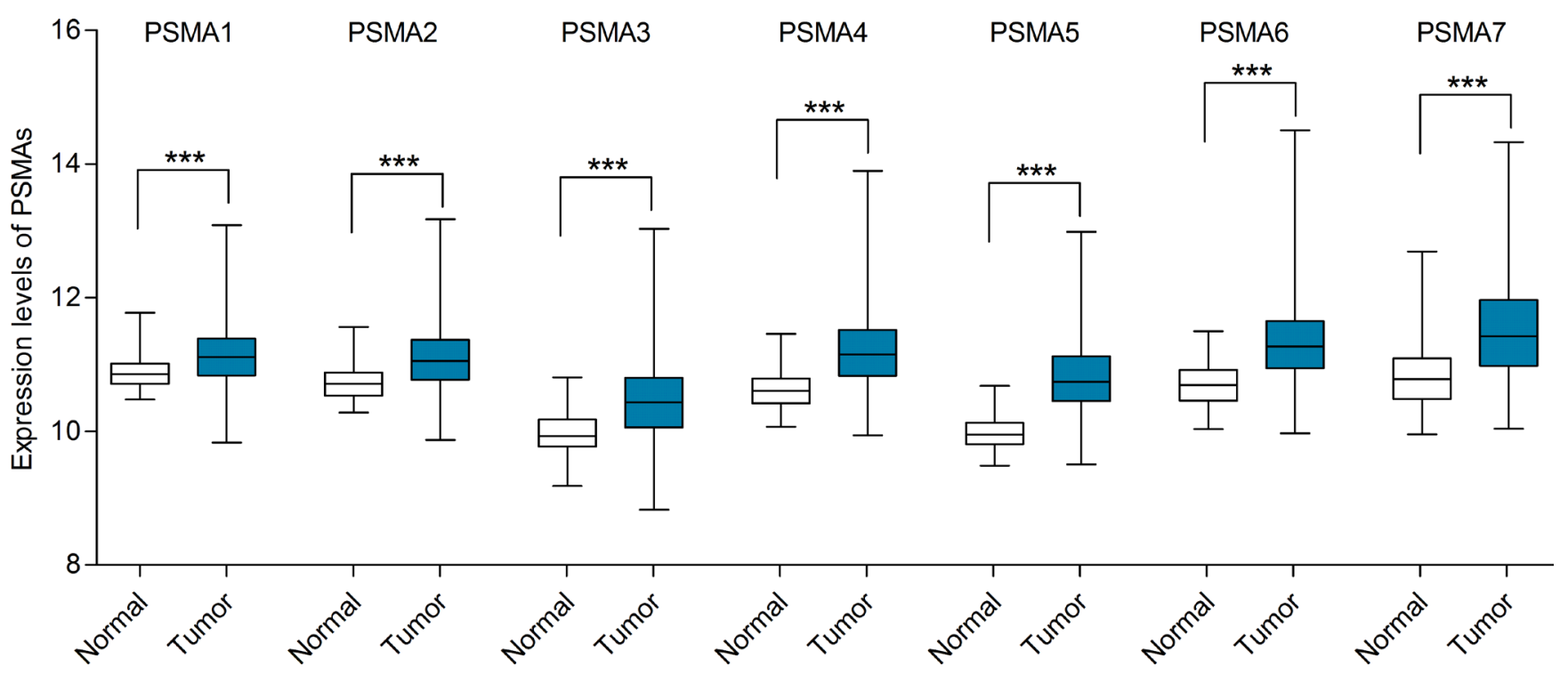

Figure 2: mRNA expression levels of PSMAs in breast cancer (TCGA mRNA HiSeq expression data). mRNA expression levels of PSMAes were investigated in 1095 breast cancer tissues and 113 normal tissues. The line in the middle represents the median value. Statistical differences were examined by two tailed Student's $t$-test. $* * * p<0.001$. 
Table 2: Correlation of PSMAs with survival outcomes in breast cancer patients

\begin{tabular}{|c|c|c|c|c|c|c|c|}
\hline Gene & Affymetrix ID & Survival outcome & No. of cases & Cut-off value & HR & $95 \%$ CI & $p$-value \\
\hline \multirow[t]{4}{*}{ PSMA1 } & 211746_x_at & OS & 1117 & 4585 & 1.18 & $0.94-1.50$ & 0.160 \\
\hline & & RFS & 3554 & 4803 & 1.48 & $1.32-1.67$ & $<0.001$ \\
\hline & & DMFS & 1609 & 5073 & 1.21 & $0.99-1.48$ & 0.067 \\
\hline & & PPS & 351 & 4606 & 0.97 & $0.75-1.26$ & 0.830 \\
\hline \multirow[t]{4}{*}{ PSMA2 } & 201316_at & OS & 1117 & 630 & 0.86 & $0.68-1.09$ & 0.202 \\
\hline & & RFS & 3554 & 609 & 1.14 & $1.02-1.28$ & 0.021 \\
\hline & & DMFS & 1609 & 669 & 0.89 & $0.73-1.09$ & 0.275 \\
\hline & & PPS & 351 & 616 & 0.85 & $0.66-1.11$ & 0.232 \\
\hline \multirow[t]{4}{*}{ PSMA3 } & 201532 at & OS & 1117 & 2981 & 1.02 & $0.81-1.29$ & 0.858 \\
\hline & & RFS & 3554 & 2893 & 1.34 & $1.19-1.50$ & $<0.001$ \\
\hline & & DMFS & 1609 & 3178 & 0.92 & $0.75-1.12$ & 0.390 \\
\hline & & PPS & 351 & 2879 & 1.15 & $0.89-1.49$ & 0.294 \\
\hline \multirow[t]{4}{*}{ PSMA4 } & 203396_at & OS & 1117 & 3423 & 1.22 & $0.96-1.55$ & 0.099 \\
\hline & & RFS & 3554 & 3069 & 1.53 & $1.36-1.71$ & $<0.001$ \\
\hline & & DMFS & 1609 & 3343 & 1.19 & $0.97-1.45$ & 0.095 \\
\hline & & PPS & 351 & 3440 & 1.12 & $0.87-1.45$ & 0.372 \\
\hline \multirow[t]{4}{*}{ PSMA5 } & 230300_at & OS & 522 & 241 & 0.58 & $0.41-0.83$ & 0.003 \\
\hline & & RFS & 1660 & 215 & 0.71 & $0.60-0.84$ & $<0.001$ \\
\hline & & DMFS & 664 & 233 & 0.61 & $0.44-0.85$ & 0.003 \\
\hline & & PPS & 140 & 225 & 0.89 & $0.61-1.31$ & 0.560 \\
\hline \multirow[t]{4}{*}{ PSMA6 } & 208805_at & OS & 1117 & 7028 & 1.01 & $0.80-1.28$ & 0.939 \\
\hline & & RFS & 3554 & 6687 & 1.39 & $1.24-1.56$ & $<0.001$ \\
\hline & & DMFS & 1609 & 7851 & 0.97 & $0.79-1.18$ & 0.740 \\
\hline & & PPS & 351 & 7157 & 0.82 & $0.63-1.06$ & 0.124 \\
\hline \multirow[t]{4}{*}{ PSMA7 } & 201114_x_at & OS & 1117 & 4160 & 1.52 & $1.20-1.93$ & $<0.001$ \\
\hline & & RFS & 3554 & 4070 & 1.50 & $1.33-1.68$ & $<0.001$ \\
\hline & & DMFS & 1609 & 4401 & 1.32 & $1.08-1.62$ & 0.007 \\
\hline & & PPS & 351 & 4349 & 1.02 & $0.79-1.32$ & 0.885 \\
\hline
\end{tabular}

HR: hazard ratio; CI: confidence interval; OS: overall survival; RFS: relapse free survival; DMFS: distant metastasis free survival; PPS: post progression survival.

\section{Transcription levels and prognostic significance of PSMAs in lung cancer}

Likewise, Oncomine database was utilized to compare the mRNA expression levels of PSMAs in lung cancer and normal tissues. With our thresholds $(p$-value $=0.01 ;$ fold change $=2$; gene rank: $10 \%$, data type: mRNA), none of the datasets revealed statistically significant differences between lung cancer group and normal tissue group for PSMA1 or PSMA4. Two comparisons of Bhattacharjee's dataset [29] indicated that the PSMA2 mRNA levels were higher in small cell lung cancer and lung carcinoid tumor tissues than in normal samples. In Yamagata's dataset [30] analyzing large cell lung carcinoma vs. normal tissue, the mRNA expression level of PSMA3 was significantly upregulated in tumor tissues. PSMA5 was also shown to be overexpressed in lung cancer according to Garber's datasets [31]. Two studies of Yamagata [30] showed that the expression level of PSMA6 was significantly elevated in lung adenocarcinoma and large cell lung carcinoma compared to normal lung tissues. As for PSMA7, the mRNA expression level was dramatically elevated in squamous cell lung carcinoma [29]. All of the results with statistically significant results are shown in Table 3. However, we noticed that the sample sizes of these datasets were relatively small. For instance, there were only five tumor cases against three normal controls in Yamagata's dataset [30]. This may diminish the statistical differences between tumor and normal tissues. Therefore, we further examined 
Table 3: Analyses of PSMAs in lung cancer

\begin{tabular}{llllccc}
\hline \multirow{2}{*}{ Gene } & \multicolumn{1}{c}{ Dataset } & \multicolumn{1}{c}{ Normal (cases) } & \multicolumn{1}{c}{ Tumor (cases) } & $\begin{array}{c}\text { Fold } \\
\text { change }\end{array}$ & $\boldsymbol{t}$-Test & $\boldsymbol{p}$-value \\
\hline PSMA2 & Bhattacharjee Lung & Lung (17) & Small Cell Lung Carcinoma (6) & 2.435 & 3.409 & $2.00 \mathrm{E}-03$ \\
& & Lung (17) & Lung Carcinoid Tumor (20) & 2.321 & 3.242 & $2.00 \mathrm{E}-03$ \\
PSMA3 & Yamagata Lung & Lung (3) & Large Cell Lung Carcinoma (5) & 2.011 & 4.233 & $3.00 \mathrm{E}-03$ \\
PSMA5 & Garber Lung & Lung (5)/Fetal Lung (1) & Large Cell Lung Carcinoma (4) & 2.172 & 3.970 & $3.00 \mathrm{E}-03$ \\
PSMA66 & Yamagata Lung & Lung (3) & Lung Adenocarcinoma (8) & 2.561 & 3.218 & $6.00 \mathrm{E}-03$ \\
& & Lung (3) & Large Cell Lung Carcinoma (5) & 2.529 & 3.823 & $6.00 \mathrm{E}-03$ \\
\multirow{2}{*}{ PSMA7 } & Bhattacharjee Lung & Lung (17) & Squamous Cell Lung Carcinoma (21) & 7.285 & 2.810 & $4.00 \mathrm{E}-03$ \\
\hline
\end{tabular}

the expression differences between lung cancer and normal tissues with TCGA mRNA HiSeq expression data. There were 109 normal samples and 1013 lung cancer samples, including 511 lung adenocarcinomas and 502 lung squamous cell carcinomas. As shown in Figure 3, the expression of all seven PSMAs in lung cancer tissues was remarkably higher than in normal tissues. Next, the mRNA expression levels of PSMAs in normal tissues were separately compared with lung adenocarcinoma and lung squamous cell carcinoma. In line with the overall comparison, the transcription levels of PSMAs were significantly increased in both lung adenocarcinoma and lung squamous cell carcinoma (Supplementary Figure S1).

We then assessed the prognostic values of PSMAs for lung cancer in KM Plotter database. OS, first progression (FP) and post progression survival (PPS) were analyzed for each gene. High mRNA expression of PSMA1 and PSMA2 was significantly associated with
PPS for lung cancer patients, with $\mathrm{HR}=0.77(0.60-0.99)$, $p=0.043$ and $\mathrm{HR}=0.65(0.51-0.84), p<0.001$, respectively. PSMA3 was found to be uncorrelated with OS, FP or PPS for lung cancer patients. In addition, high mRNA level of PSMA4 was significantly associated with FP (HR $=0.80 ; 95 \%$ CI: $0.66-0.97 ; p=0.021)$ but not OS or PPS. Interestingly, increased mRNA level of PSMA5 predicted better OS $(\mathrm{HR}=0.51 ; 95 \%$ CI: $0.43-0.60$; $p<0.001)$, FP ( $\mathrm{HR}=0.71 ; 95 \%$ CI: $0.54-0.93 ; p=0.012)$ and PPS (HR $=0.64 ; 95 \%$ CI: $0.42-0.99 ; p=0.042)$. On the contrary, high PSMA6 expression was associated with worse OS (HR $=1.33 ; 95 \%$ CI: $0.1 .17-1.51 ; p<0.001)$ and FP (HR $=1.37 ; 95 \%$ CI: $1.13-1.66 ; p=0.001)$ but not PPS for lung cancer patients. PSMA7 was also found to be significantly associated with worse $\mathrm{OS}$ ( $\mathrm{HR}=1.28$; $95 \%$ CI: $1.13-1.45 ; p<0.001)$ but not FS or PPS. The prognostic effects of the seven genes are summarized in Table 4. In a further analysis, patients were stratified

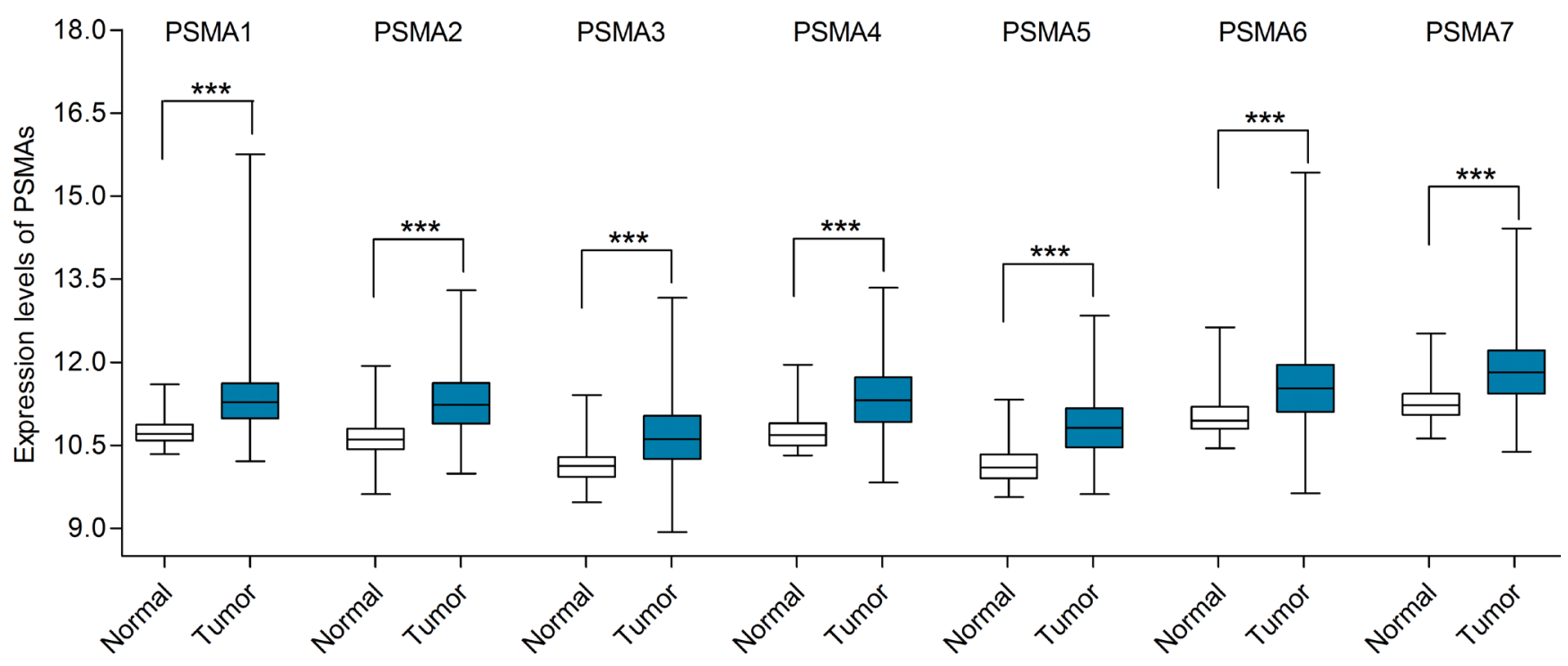

Figure 3: mRNA expression levels of PSMAs in lung cancer (TCGA mRNA HiSeq expression data). mRNA expression levels of PSMAs were investigated in 1013 lung cancer tissues and 109 normal tissues. The line in the middle represents the median value. Statistical differences were examined by two tailed Student's $t$-test. *** $p<0.001$. 
Table 4: Correlation of PSMAs with survival outcomes in lung cancer patients

\begin{tabular}{|c|c|c|c|c|c|c|c|}
\hline Gene & Affymetrix ID & Survival outcome & No. of cases & Cut-off value & HR & $95 \%$ CI & $p$-value \\
\hline \multirow[t]{3}{*}{ PSMA1 } & 211746_x_at & OS & 1926 & 5033 & 0.94 & $0.83-1.06$ & 0.319 \\
\hline & & FP & 982 & 5033 & 0.83 & $0.69-1.00$ & 0.055 \\
\hline & & PPS & 344 & 4645 & 0.77 & $0.60-0.99$ & 0.043 \\
\hline \multirow[t]{3}{*}{ PSMA2 } & 201316_at & OS & 1926 & 547 & 0.89 & $0.79-1.01$ & 0.075 \\
\hline & & FP & 982 & 474 & 0.91 & $0.76-1.11$ & 0.361 \\
\hline & & PPS & 344 & 437 & 0.65 & $0.51-0.84$ & $<0.001$ \\
\hline \multirow[t]{3}{*}{ PSMA3 } & 201532_at & OS & 1926 & 3495 & 1.08 & $0.95-1.23$ & 0.213 \\
\hline & & FP & 982 & 2988 & 1.12 & $0.93-1.36$ & 0.227 \\
\hline & & PPS & 344 & 2871 & 0.83 & $0.64-1.07$ & 0.142 \\
\hline \multirow[t]{3}{*}{ PSMA4 } & 203396_at & OS & 1926 & 3381 & 0.99 & $0.88-1.13$ & 0.930 \\
\hline & & FP & 982 & 2943 & 0.80 & $0.66-0.97$ & 0.021 \\
\hline & & PPS & 344 & 2460 & 1.13 & $0.87-1.45$ & 0.359 \\
\hline \multirow[t]{3}{*}{ PSMA5 } & 230300_at & OS & 1145 & 138 & 0.51 & $0.43-0.60$ & $<0.001$ \\
\hline & & FP & 596 & 212 & 0.71 & $0.54-0.93$ & 0.012 \\
\hline & & PPS & 138 & 313 & 0.64 & $0.42-0.99$ & 0.042 \\
\hline \multirow[t]{3}{*}{ PSMA6 } & 208805_at & OS & 1926 & 7466 & 1.33 & $1.17-1.51$ & $<0.001$ \\
\hline & & FP & 982 & 7080 & 1.37 & $1.13-1.66$ & 0.001 \\
\hline & & PPS & 344 & 7095 & 1.21 & $0.94-1.56$ & 0.132 \\
\hline \multirow[t]{3}{*}{ PSMA7 } & 201114_x_at & OS & 1926 & 4431 & 1.28 & $1.13-1.45$ & $<0.001$ \\
\hline & & FP & 982 & 3799 & 0.89 & $0.74-1.08$ & 0.235 \\
\hline & & PPS & 344 & 3737 & 1.20 & $0.93-1.55$ & 0.151 \\
\hline
\end{tabular}

HR: hazard ratio; CI: confidence interval; OS: overall survival; FP: first progression; PPS: post progression survival.

by histological type, tumor stage and tumor grade (Supplementary Table S3). The results showed that most of the PSMAs were significantly correlated with prognosis in adenocarcinoma, but not in squamous cell carcinoma. When grouped by tumor stage, all seven PSMAs showed different prognostic values in stage 1 , whereas only PSMA1, PSMA2 and PSMA5 were correlated with OS or PPS in stage 2. Finally, analyses were performed for tumor grades I and II. However, only PSMA1 and PSMA3 were significantly associated with poor outcomes in patients with tumor grade II.

\section{Transcription levels and prognostic significance of PSMAs in gastric cancer}

In Oncomine database, there were five datasets that compared the expression differences between gastric cancer and normal tissues for PSMA1-6, and four datasets for PSMA7. No statistically significant differences of mRNA expression were observed between tumor and normal tissues for PSMA1-6 in any of the five datasets with the thresholds we applied. However, compared with 31 gastric mucosa samples, the mRNA expression level of PSMA7 was significantly upregulated in gastric intestinal type adenocarcinoma (cases $=26$, fold change $=2.516$, $p<0.001$ ) and gastric mixed adenocarcinoma (cases $=4$, fold change $=2.555, p<0.001)$ in DErrico's dataset [32]. Considering the limited number of cases in Oncomine, the TCGA database involving 384 gastric cancer and 37 normal samples were further used to confirm the potential expression difference of PSMAs between tumors and normal tissues. All of the seven genes were remarkably overexpressed in gastric cancer compared with normal tissues (Figure 4).

The correlations between PSMAs and survival outcomes of gastric cancer patients involving OS and FP were then determined in KM Plotter database. The prognostic effects of the seven genes are shown in Table 5. Intriguingly, high mRNA expression levels of all PSMAs were significantly related to better OS with $\mathrm{HR}=0.67$ $(0.56-0.79), p<0.001$ for PSMA1; HR $=0.65(0.55-0.78)$, $p<0.001$ for PSMA2; HR $=0.77(0.65-0.91), p=0.002$ for PSMA3; HR $=0.66(0.56-0.79), p<0.001$ for PSMA4; $\mathrm{HR}=0.80(0.65-1.00), p=0.047$ for PSMA5; $\mathrm{HR}=0.62$ $(0.52-0.73), p<0.001$ for PSMA6; HR $=0.64(0.54-0.76)$, $p<0.001$ for PSMA7, and better FP with HR $=0.62$ (0.39-0.61), $p<0.001$ for PSMA1; HR $=0.61(0.49-0.74)$, $p<0.001$ for PSMA2; HR $=0.69(0.57-0.85), p<0.001$ 
for PSMA3; HR = $0.64(0.52-0.78), p<0.001$ for PSMA4; $\mathrm{HR}=0.66(0.52-0.84), p<0.001$ for PSMA5; HR $=0.58$ $(0.48-0.72), p<0.001$ for PSMA6; and HR $=0.70(0.57-$ $0.85), p<0.001$ for PSMA7. Next, the prognostic ability of PSMAs expression was investigated in different tumor stages and HER2 status of gastric cancer. As shown in Supplementary Table S4, a high expression of PSMA1-4 and PSMA6-7 predicted better prognosis in stage 3, but only PSMA6, PSMA5 and PSMA7 were associated with outcomes in stage 1, stage 2 and stage 4, respectively. In line with the overall cohort, the expression of all PSMAs was significantly correlated with better prognosis in the HER2-negative group. However, only PSMA2, PSMA5 and PSMA7 expression were correlated with OS or FP in the HER2-positive group.

\section{Transcription levels and prognostic significance of PSMAs in several other cancers}

As for ovarian cancer, the Oncomine database revealed no significant differences in the mRNA expression of PSMAs between ovarian tumors and normal tissues (Figure 1). Meanwhile, the mRNA levels of PSMAs could not be compared between tumors and normal tissues in TCGA database due to the lack of normal ovarian samples. Next, we examined the prognostic significance of PSMAs in KM Plotter database, and the results showed that only PSMA1 was associated with PPS $(\mathrm{HR}=0.83 ; 95 \% \mathrm{CI}: 0.70-1.00 ; p=0.044)$ for ovarian cancer patients (Table 6).

In colorectal cancer, it was previously reported that the mRNA and protein expression levels of PSMA7 were much higher than in normal tissue, and a high protein expression of PSMA7 was significantly associated with worse OS for colorectal cancer patients [19]. In line with this study, eight comparisons from five datasets including Ki [33], Skrzypczak [34], TCGA, Skrzypczak 2 [34] and Hong [35] revealed that the mRNA level of PSMA7 was increased in different types of colorectal cancer compared with normal tissues. Moreover, PSMA3 and PSMA4 were also upregulated in rectal adenoma compared with normal tissues from Sabates-Bellver's datasets [36] (Table 7). In the TCGA database, PSMA1-5 and PSMA7 were overexpressed in colorectal cancer tissues examined by mRNA HiSeq expression data (Figure 5A). Alternatively, the prognostic values of PSMAs were then determined by the PrognScan database because survival data of colorectal cancer was absent in KM Plotter. The probe IDs selected in PrognScan database were consistent with the desired Affymetrix IDs in KM plotter. The results showed that only elevated mRNA of PSMA7 predicted worse DFS $(\mathrm{HR}=3.02,95 \% \mathrm{CI}: 1.34-6.81, p=0.008)$ in Smith's study [37]. The correlations between the mRNA expression of PSMAs and survival outcomes of colorectal cancer patients reported by PrognScan database are summarized in Table 8.

For bladder cancer, Oncomine included only four datasets that were available for cancer vs. normal analysis, of which Dyrskjot [38] and Sanchez-Carbayo's dataset [39] respectively showed elevated expression levels of PSMA2 and PSMA5 in bladder cancer compared to normal tissues (Table 7). However, all seven genes were overexpressed in cancer tissues examined by mRNA HiSeq expression data in the TCGA database (Figure 5B). In the PrognScan database, only one study for each gene was retrieved, but no significant association was found between PSMAs and OS for bladder cancer patients (Table 9).

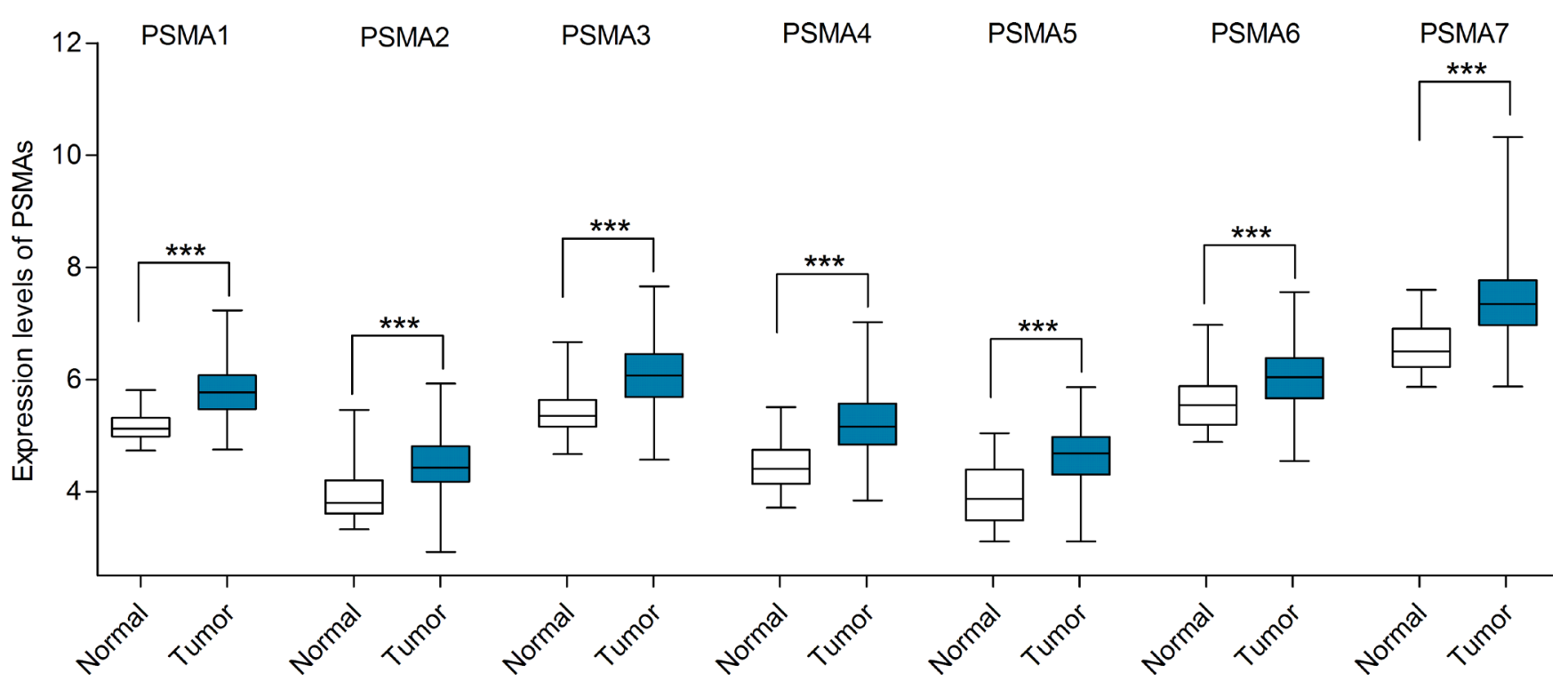

Figure 4: mRNA expression levels of PSMAs in gastric cancer (TCGA mRNA HiSeq expression data). mRNA expression levels of PSMAs were investigated in 384 gastric cancer tissues and 37 normal tissues. The line in the middle represents the median value. Statistical differences were examined by two tailed student's $t$-test. $* * * p<0.001$. 
Table 5: Correlation of PSMAs with survival outcomes in gastric cancer patients

\begin{tabular}{cccccccc}
\hline Gene & Affymetrix ID & Survival outcome & No. of cases & Cut-off value & HR & $\mathbf{9 5 \%}$ CI & $\boldsymbol{p}$-value \\
\hline PSMA1 & 211746_x_at & OS & 876 & 438 & 0.67 & $0.56-0.79$ & $<\mathbf{0 . 0 0 1}$ \\
& & FP & 641 & 321 & 0.62 & $0.39-0.61$ & $<\mathbf{0 . 0 0 1}$ \\
PSMA2 & \multirow{2}{*}{ 201316_at } & OS & 876 & 438 & 0.65 & $0.55-0.78$ & $<\mathbf{0 . 0 0 1}$ \\
& & FP & 641 & 321 & 0.61 & $0.49-0.74$ & $<\mathbf{0 . 0 0 1}$ \\
PSMA3 & \multirow{2}{*}{ 201532_at } & OS & 876 & 437 & 0.77 & $0.65-0.91$ & $\mathbf{0 . 0 0 2}$ \\
& & FP & 641 & 320 & 0.69 & $0.57-0.85$ & $<\mathbf{0 . 0 0 1}$ \\
PSMA4 & \multirow{2}{*}{ 203396_at } & OS & 876 & 438 & 0.66 & $0.56-0.79$ & $<\mathbf{0 . 0 0 1}$ \\
& & FP & 641 & 321 & 0.64 & $0.52-0.78$ & $<\mathbf{0 . 0 0 1}$ \\
PSMA5 & \multirow{2}{*}{ 230300_at } & OS & 631 & 315 & 0.80 & $0.65-1.00$ & $\mathbf{0 . 0 4 7}$ \\
& & FP & 522 & 260 & 0.66 & $0.52-0.84$ & $<\mathbf{0 . 0 0 1}$ \\
PSMA6 & \multirow{2}{*}{ 208805_at } & OS & 876 & 438 & 0.62 & $0.52-0.73$ & $<\mathbf{0 . 0 0 1}$ \\
& & FP & 641 & 321 & 0.58 & $0.48-0.72$ & $<\mathbf{0 . 0 0 1}$ \\
PSMA7 & 201114_x_at & OS & 876 & 438 & 0.64 & $0.54-0.76$ & $<\mathbf{0 . 0 0 1}$ \\
& & FP & 641 & 320 & 0.70 & $0.57-0.85$ & $<\mathbf{0 . 0 0 1}$ \\
\hline
\end{tabular}

HR: hazard ratio; CI: confidence interval; OS: overall survival; FP: first progression.

Table 6: Correlation of PSMAs with survival outcomes in ovarian cancer patients

\begin{tabular}{|c|c|c|c|c|c|c|c|}
\hline Gene & Affymetrix ID & Survival outcome & No. of cases & Cut-off value & HR & $95 \% \mathrm{CI}$ & $p$-value \\
\hline \multirow{3}{*}{ PSMA1 } & 211746_x_at & OS & 1582 & 4834 & 1.01 & $0.88-1.15$ & 0.893 \\
\hline & & PFS & 1306 & 4898 & 1.03 & $0.90-1.17$ & 0.660 \\
\hline & & PPS & 708 & 5025 & 0.83 & $0.70-1.00$ & 0.044 \\
\hline \multirow[t]{3}{*}{ PSMA2 } & 201316_at & OS & 1582 & 711 & 1.12 & $0.98-1.27$ & 0.109 \\
\hline & & PFS & 1306 & 724 & 0.96 & $0.84-1.09$ & 0.514 \\
\hline & & PPS & 708 & 725 & 1.03 & $0.86-1.23$ & 0.759 \\
\hline \multirow[t]{3}{*}{ PSMA3 } & 201532_at & OS & 1582 & 3015 & 1.02 & $0.89-1.17$ & 0.758 \\
\hline & & PFS & 1306 & 3186 & 1.13 & $0.99-1.29$ & 0.072 \\
\hline & & PPS & 708 & 3323 & 1.02 & $0.85-1.22$ & 0.859 \\
\hline \multirow[t]{3}{*}{ PSMA4 } & 203396_at & OS & 1582 & 3779 & 0.98 & $0.85-1.12$ & 0.717 \\
\hline & & PFS & 1306 & 3840 & 0.99 & $0.87-1.13$ & 0.853 \\
\hline & & PPS & 708 & 3946 & 0.93 & $0.78-1.12$ & 0.453 \\
\hline \multirow[t]{3}{*}{ PSMA5 } & 230300_at & OS & 580 & 164 & 0.91 & $0.73-1.14$ & 0.428 \\
\hline & & PFS & 484 & 150 & 0.85 & $0.69-1.05$ & 0.125 \\
\hline & & PPS & 307 & 146 & 0.99 & $0.76-1.30$ & 0.944 \\
\hline \multirow[t]{3}{*}{ PSMA6 } & 208805_at & OS & 1582 & 7678 & 1.02 & $0.89-1.17$ & 0.771 \\
\hline & & PFS & 1306 & 8209 & 1.08 & $0.94-1.23$ & 0.279 \\
\hline & & PPS & 708 & 8516 & 0.9 & $0.75-1.08$ & 0.251 \\
\hline \multirow[t]{3}{*}{ PSMA7 } & 201114_x_at & OS & 1582 & 4333 & 1.12 & $0.98-1.28$ & 0.091 \\
\hline & & PFS & 1306 & 4671 & 1.11 & $0.97-1.27$ & 0.121 \\
\hline & & PPS & 708 & 4793 & 0.92 & $0.77-1.10$ & 0.381 \\
\hline
\end{tabular}

HR: hazard ratio; CI: confidence interval; OS: overall survival; PFS: progression free survival; PPS: post progression survival. 
Table 7: Analyses of PMSAs in multiple cancers

\begin{tabular}{|c|c|c|c|c|c|c|c|}
\hline Cancer & Gene & Dataset & Normal (Cases) & Tumor (Cases) & $\begin{array}{l}\text { Fold } \\
\text { change }\end{array}$ & $t$-Test & $p$-value \\
\hline \multirow[t]{10}{*}{$\begin{array}{l}\text { Colorectal } \\
\text { cancer }\end{array}$} & PSMA3 & Sabates-Bellver Colon & Colon (25)/Rectum (7) & Rectal Adenoma (7) & 2.112 & 7.162 & $2.47 \mathrm{E}-05$ \\
\hline & PSMA4 & Sabates-Bellver Colon & Colon (25)/Rectum (7) & Rectal Adenoma (7) & 2.225 & 9.131 & $5.40 \mathrm{E}-06$ \\
\hline & PSMA7 & Ki Colon & Colon (28)/Liver (13) & Colon Adenocarcinoma (50) & 2.124 & 10.045 & $2.01 \mathrm{E}-15$ \\
\hline & & Skrzypczak Colorectal & Colorectal Tissue (24) & Colorectal Carcinoma (36) & 2.111 & 8.780 & $1.95 \mathrm{E}-12$ \\
\hline & & TCGA Colorectal & Colon (19)/Rectum (3) & Rectal Adenocarcinoma (60) & 2.407 & 13.228 & $2.88 \mathrm{E}-20$ \\
\hline & & & Colon (19)/Rectum (3) & Colon Adenocarcinoma (101) & 2.463 & 15.110 & $2.93 \mathrm{E}-21$ \\
\hline & & & Colon (19)/Rectum (3) & Cecum Adenocarcinoma (22) & 2.044 & 7.710 & $3.76 \mathrm{E}-09$ \\
\hline & & Skrzypczak Colorectal 2 & Colon (10) & Colon Carcinoma (5) & 3.018 & 13.959 & $1.70 \mathrm{E}-09$ \\
\hline & & & Colon (10) & Colon Carcinoma (5) & 3.125 & 11.038 & $1.81 \mathrm{E}-06$ \\
\hline & & Hong Colorectal & Colon (12) & Colorectal Carcinoma (70) & 3.290 & 13.308 & $1.05 \mathrm{E}-12$ \\
\hline \multirow[t]{2}{*}{ Bladder cancer } & PSMA2 & Dyrskjot Bladder 3 & Bladder (9)/Bladder Mucosa (5) & Infiltrating Bladder Urothelial Carcinoma (13) & 2.984 & 5.672 & $3.12 \mathrm{E}-05$ \\
\hline & PSMA5 & $\begin{array}{l}\text { Sanchez-Carbayo } \\
\text { Bladder } 2\end{array}$ & Bladder (48) & Superficial Bladder Cancer (28) & 2.385 & 8.739 & $4.05 \mathrm{E}-12$ \\
\hline \multirow[t]{10}{*}{ Kidney cancer } & PSMA1 & Jones Renal & Kidney (23) & Renal Pelvis Urothelial Carcinoma (8) & 2.128 & 10.933 & 5.73E-09 \\
\hline & PSMA2 & Jones Renal & Kidney (23) & Renal Pelvis Urothelial Carcinoma (8) & 2.325 & 9.303 & $8.95 \mathrm{E}-07$ \\
\hline & PSMA3 & Jones Renal & Kidney (23) & Renal Pelvis Urothelial Carcinoma (8) & 2.198 & 7.719 & $2.26 \mathrm{E}-06$ \\
\hline & & Yusenko Renal & Fetal Kidney (2)/Kidney (3) & Renal Wilms Tumor (4) & 2.144 & 3.749 & $4.00 \mathrm{E}-03$ \\
\hline & PSMA4 & Jones Renal & Kidney (23) & Renal Pelvis Urothelial Carcinoma (8) & 2.179 & 7.243 & $1.52 \mathrm{E}-05$ \\
\hline & PSMA6 & Yusenko Renal & Fetal Kidney (2)/Kidney (3) & Renal Wilms Tumor (4) & 2.192 & 3.962 & $3.00 \mathrm{E}-03$ \\
\hline & PSMA7 & Higgins Renal & Kidney (2) & Papillary Renal Cell Carcinoma (4) & 2.007 & 4.515 & $6.00 \mathrm{E}-03$ \\
\hline & & Yusenko Renal & Fetal Kidney (2)/Kidney (3) & Chromophobe Renal Cell Carcinoma (4) & 3.061 & 6.192 & $2.68 \mathrm{E}-04$ \\
\hline & & & Fetal Kidney (2)/Kidney (3) & Renal Oncocytoma (4) & 2.116 & 5.638 & $1.00 \mathrm{E}-03$ \\
\hline & & & Fetal Kidney (2)/Kidney (3) & Renal Wilms Tumor (4) & 2.492 & 3.824 & $6.00 \mathrm{E}-03$ \\
\hline \multirow[t]{7}{*}{ Melanoma } & PSMA1 & Haqq Melanoma & Skin (3) & Melanoma (5) & 2.229 & 7.928 & $6.57 \mathrm{E}-04$ \\
\hline & PSMA3 & Haqq Melanoma & Skin (3) & Melanoma (6) & 2.235 & 6.195 & $3.39 \mathrm{E}-04$ \\
\hline & PSMA4 & Talantov Melanoma & Skin (7) & Cutaneous Melanoma (45) & 3.418 & 11.368 & $1.60 \mathrm{E}-08$ \\
\hline & PSMA5 & Haqq Melanoma & Skin (3) & Non-Neoplastic Nevus (9) & 2.353 & 7.140 & $2.79 \mathrm{E}-05$ \\
\hline & & & Skin (3) & Melanoma (6) & 3.002 & 5.306 & 8.61E-04 \\
\hline & PSMA6 & Haqq Melanoma & Skin (3) & Non-Neoplastic Nevus (9) & 3.005 & 7.375 & 7.24E-04 \\
\hline & & & Skin (3) & Melanoma (6) & 3.296 & 5.624 & 4.12E-04 \\
\hline
\end{tabular}

In kidney cancer, Jones's dataset [40] showed that the mRNA expression levels of PSMA1-4 were upregulated in renal pelvis urothelial carcinoma compared with normal kidney tissues (Table 7). In Yusenko's dataset [41], the transcription levels of both PSMA3 and PSMA6 were higher in renal Wilms tumor than in normal tissues. PSMA7 was overexpressed in kidney cancer analyzed by Higgins and Yusenko's datasets [41, 42]. Consistent with the trend seen in Oncomine, the expression levels of PSMA1-4 and PSMA6-7 were significantly increased in 889 kidney cancers compared with 129 normal tissues in the TCGA mRNA HiSeq expression data (Figure 5C). Furthermore, analyses were also performed in different subtypes of kidney cancer including chromophobe cell, clear cell and papillary cell carcinoma by the TCGA data (Supplementary Figure S2). Compared with normal kidney tissue, PSMA1, PSMA3 and PSMA7 were upregulated in kidney chromophobe cell carcinoma, whereas PSMA5 was downregulated. The expression levels of PSMA1-3 and PSMA6 were higher in kidney clear cell carcinoma than in normal samples. Except for PSMA3, all PSMAs were significantly upregulated in kidney papillary cell carcinoma compared with normal tissue. However, since survival data was not available in the KM Plotter or PrognScan databases, we were unable to investigate the prognostic effects of PSMAs in kidney cancer.

With respect to melanoma, the mRNA expression levels of PSMA1, PSMA3, PSMA5 and PSMA6 were upregulated in melanoma compared with normal tissues according to Haqq's dataset [43] (Table 7). In Talantov's dataset [44], PSMA4 was higher in 45 cutaneous melanomas than in seven normal skin samples. However, 

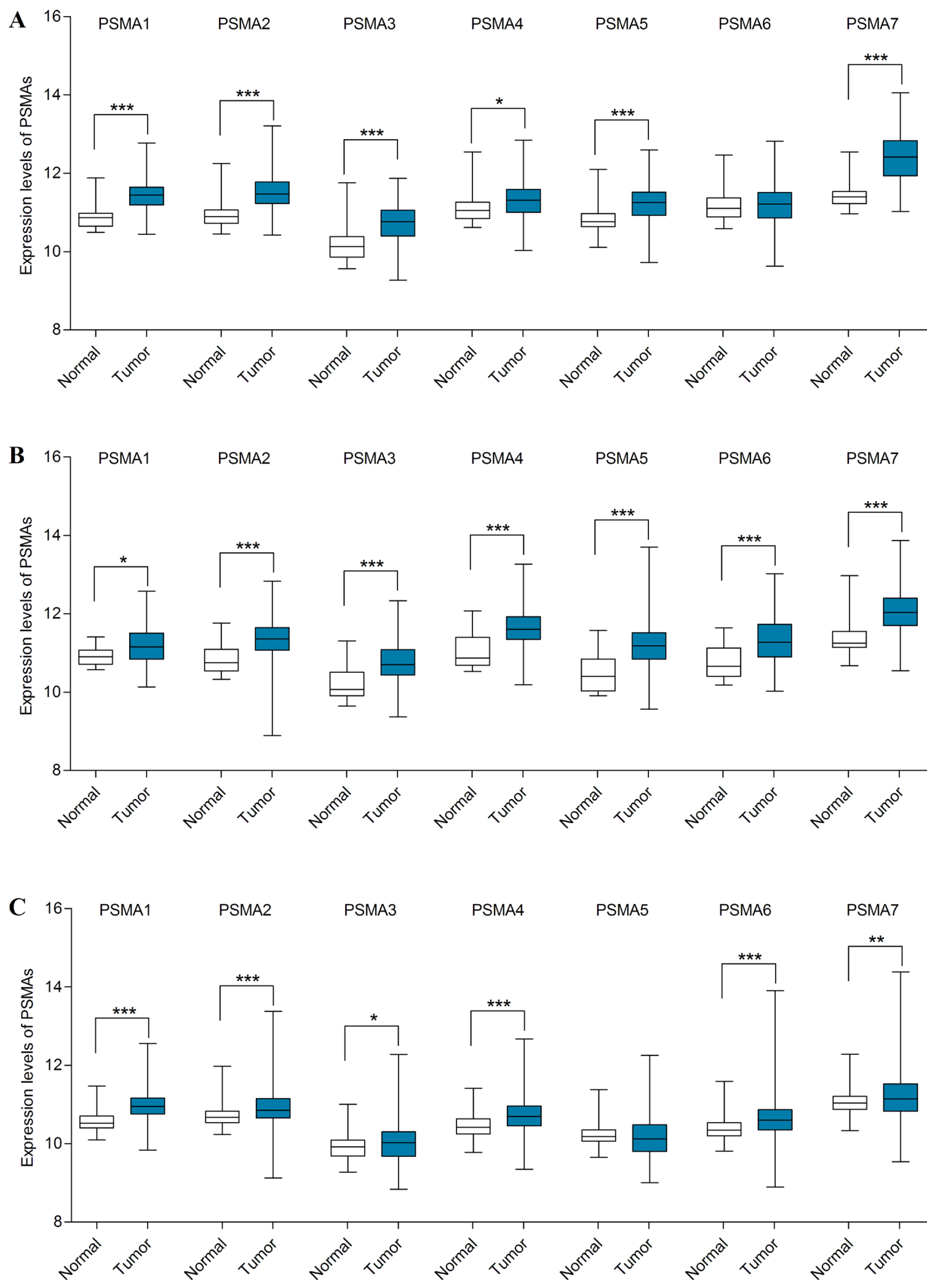

Figure 5: mRNA expression levels of PSMAs in colorectal, bladder and kidney cancer (TCGA mRNA HiSeq expression data). (A) mRNA expression levels of PSMAs were investigated in 380 colorectal cancers and 50 normal tissues. (B) mRNA expression levels of PSMAs were investigated in 407 bladder cancers and 19 normal tissues. (C) mRNA expression levels of PSMAs were investigated in 889 kidney cancers and 129 normal tissues. The line in the middle represents the median value. Statistical differences were examined by two tailed Student's $t$-test. $* p<0.05 ; * p<0.01 ; * * p<0.001$. 
Table 8: Correlation of PSMAs with survival outcomes in colorectal cancer patients

\begin{tabular}{|c|c|c|c|c|c|c|c|}
\hline Gene & Affymetrix ID & Dataset & Survival outcome & No. of cases & HR & $95 \%$ CI & $p$-value \\
\hline \multirow[t]{9}{*}{ PSMA1 } & 211746_x_at & GSE12945 & OS & 62 & 1.01 & $0.88-1.15$ & 0.714 \\
\hline & & & DFS & 51 & 0.80 & $0.25-2.59$ & 0.145 \\
\hline & & GSE17536 & OS & 177 & 0.84 & $0.33-2.16$ & 0.717 \\
\hline & & & DFS & 145 & 1.14 & $0.31-4.23$ & 0.849 \\
\hline & & & DSS & 177 & 0.54 & $0.19-1.59$ & 0.264 \\
\hline & & GSE14333 & DFS & 226 & 0.72 & $0.16-3.12$ & 0.656 \\
\hline & & GSE17537 & OS & 55 & 2.36 & $0.57-9.83$ & 0.236 \\
\hline & & & DFS & 55 & 3.51 & $0.73-16.86$ & 0.117 \\
\hline & & & DSS & 49 & 3.21 & $0.38-27.32$ & 0.285 \\
\hline \multirow[t]{9}{*}{ PSMA2 } & 201316_at & GSE12945 & OS & 62 & 0.45 & $0.11-1.79$ & 0.258 \\
\hline & & & DFS & 51 & 0.37 & $0.04-3.14$ & 0.360 \\
\hline & & GSE17536 & OS & 177 & 1.28 & $0.66-2.48$ & 0.460 \\
\hline & & & DFS & 145 & 1.03 & $0.40-2.67$ & 0.951 \\
\hline & & & DSS & 177 & 1.09 & $0.51-2.33$ & 0.831 \\
\hline & & GSE14333 & DFS & 226 & 0.63 & $0.30-1.33$ & 0.225 \\
\hline & & GSE17537 & OS & 55 & 2.74 & $0.93-8.01$ & 0.066 \\
\hline & & & DFS & 55 & 2.48 & $0.77-8.01$ & 0.128 \\
\hline & & & DSS & 49 & 2.67 & $0.66-10.76$ & 0.168 \\
\hline \multirow[t]{9}{*}{ PSMA3 } & 201532_at & GSE12945 & OS & 62 & 1.23 & $0.66-2.30$ & 0.522 \\
\hline & & & DFS & 51 & 0.95 & $0.41-2.18$ & 0.898 \\
\hline & & GSE17536 & OS & 177 & 1.72 & $0.93-3.18$ & 0.083 \\
\hline & & & DFS & 145 & 1.36 & $0.59-3.13$ & 0.466 \\
\hline & & & DSS & 177 & 1.83 & $0.89-3.73$ & 0.099 \\
\hline & & GSE14333 & DFS & 226 & 0.91 & $0.44-1.89$ & 0.798 \\
\hline & & GSE17537 & OS & 55 & 1.24 & $0.48-3.22$ & 0.652 \\
\hline & & & DFS & 55 & 1.16 & $0.43-3.13$ & 0.766 \\
\hline & & & DSS & 49 & 1.02 & $0.25-4.07$ & 0.980 \\
\hline \multirow[t]{9}{*}{ PSMA4 } & 203396_at & GSE12945 & OS & 62 & 2.09 & $0.64-6.78$ & 0.220 \\
\hline & & & DFS & 51 & 1.37 & $0.27-7.03$ & 0.706 \\
\hline & & GSE17536 & OS & 177 & 1.40 & $0.79-2.48$ & 0.245 \\
\hline & & & DFS & 145 & 0.79 & $0.36-1.72$ & 0.547 \\
\hline & & & DSS & 177 & 1.26 & $0.65-2.45$ & 0.495 \\
\hline & & GSE14333 & DFS & 226 & 0.52 & $0.24-1.13$ & 0.098 \\
\hline & & GSE17537 & OS & 55 & 1.20 & $0.35-4.15$ & 0.768 \\
\hline & & & DFS & 55 & 1.56 & $0.42-5.88$ & 0.509 \\
\hline & & & DSS & 49 & 1.77 & $0.34-9.33$ & 0.500 \\
\hline PSMA5 & 230300_at & Not available & & & & & \\
\hline \multirow[t]{5}{*}{ PSMA6 } & 208805_at & GSE12945 & OS & 62 & 2.38 & $0.54-10.48$ & 0.253 \\
\hline & & & DFS & 51 & 2.87 & $0.30-27.71$ & 0.363 \\
\hline & & GSE17536 & OS & 177 & 1.40 & $0.66-2.96$ & 0.380 \\
\hline & & & DFS & 145 & 0.87 & $0.31-2.43$ & 0.790 \\
\hline & & & DSS & 177 & 1.06 & $0.45-2.48$ & 0.902 \\
\hline
\end{tabular}




\begin{tabular}{|c|c|c|c|c|c|c|c|}
\hline & & GSE14333 & DFS & 226 & 0.42 & $0.17-1.03$ & 0.059 \\
\hline & & GSE17537 & OS & 55 & 1.16 & $0.37-3.66$ & 0.798 \\
\hline & & & DFS & 55 & 0.98 & $0.31-3.11$ & 0.976 \\
\hline & & & DSS & 49 & 1.15 & $0.19-6.99$ & 0.880 \\
\hline \multirow[t]{9}{*}{ PSMA7 } & 201114_x_at & GSE12945 & OS & 62 & 1.32 & $0.63-2.78$ & 0.466 \\
\hline & & & DFS & 51 & 1.71 & $0.52-5.56$ & 0.374 \\
\hline & & GSE17536 & OS & 177 & 0.85 & $0.49-1.46$ & 0.555 \\
\hline & & & DFS & 145 & 0.49 & $0.22-1.09$ & 0.082 \\
\hline & & & DSS & 177 & 0.56 & $0.30-1.06$ & 0.073 \\
\hline & & GSE14333 & DFS & 226 & 0.61 & $0.34-1.07$ & 0.086 \\
\hline & & GSE17537 & OS & 55 & 1.21 & $0.62-2.35$ & 0.576 \\
\hline & & & DFS & 55 & 3.02 & $1.34-6.81$ & 0.008 \\
\hline & & & DSS & 49 & 1.78 & $0.70-4.50$ & 0.224 \\
\hline
\end{tabular}

HR: hazard ratio; CI: confidence interval; OS: overall survival; DFS: diseases free survival; DSS: disease specific survival.

Table 9: Correlation of PSMAs with survival outcomes in bladder cancer

\begin{tabular}{lllccccc}
\hline Gene & Affymetrix ID & Dataset & Survival outcome & No. of cases & HR & 95\% CI & $p$-value \\
\hline PSMA1 & 211746_x_at & GSE5287 & OS & 30 & 1.04 & $0.44-2.46$ & 0.928 \\
PSMA2 & 201316_at & GSE5287 & OS & 30 & 0.28 & $0.02-3.62$ & 0.329 \\
PSMA3 & 201532_at & GSE5287 & OS & 30 & 1.54 & $0.51-4.65$ & 0.446 \\
PSMA4 & 203396_at & GSE5287 & OS & 30 & 1.46 & $0.54-3.96$ & 0.453 \\
PSMA5 & Not available & & & & & & \\
PSMA6 & 208805_at & GSE5287 & OS & 30 & 1.77 & $0.59-5.26$ & 0.307 \\
PSMA7 & 201114_x_at & GSE5287 & OS & 30 & 0.9 & $0.31-2.67$ & 0.854 \\
\hline
\end{tabular}

HR: hazard ratio; CI: confidence interval; OS: overall survival.

we were not able to compare the expression difference of PSMAs between tumors and normal tissues in the TCGA database due to the lack of normal samples. Subsequently, the PrognScan database was used to investigate the prognostic significance of the PSMAs in melanoma. As shown in Table 10, PSMA1, PSMA3 and PSMA7 were significantly associated with survival outcomes in melanoma patients $[45,46]$.

In head and neck cancer, there were a total of 15 datasets investigating PSMAs mRNA expression in tumor and normal tissues in Oncomine database. In Pyeon's multi-cancer datasets [47], the mRNA expression levels of all seven genes were shown to be upregulated in several kinds of head and neck cancers compared with normal tissues (Table 11). PSMA4 mRNA was also found to be significantly elevated in datasets including Frierson [48], Talbot [49], Cromer [50] and Estilo [51]. In addition, Ginos's dataset [52] showed an increased expression level of PSMA5 in head and neck squamous cell carcinoma. However, since the survival data was absent in KM Plotter and PrognScan, we could not investigate the prognostic effects of PSMAs in head and neck cancer.

\section{DISCUSSION}

The proteasome is engaged in the degradation of numerous proteins involved in critical physiological functions in human cancers. Elevated proteasome activity has frequently been detected in different types of tumor cells, which is consistent with the fact that malignant cells are generally more sensitive to proteasome inhibitors than non-cancerous cells $[53,54]$. Along with high proteasome activity, the expression of many proteasome subunits has been reported to be upregulated in different kinds of tumors compared with normal tissues, thus indicating that elevated proteasome subunits might be the underlying mechanism of high proteasome activity and therefore may represent key points for drugs targeting proteasome in cancer [54-56]. In this context, Deng and colleagues demonstrated that the expression of six proteasome subunits including PSMA1, PSMB5, PSMD1, PSMD2, PSMD8 and PSMD11 was increased over three-fold in breast cancer tissues when compared to adjacent normal tissues [8]. Upregulation of PSMA6, PSMB4, PSMC2 and PSMD12 was also observed in hepatocellular carcinomas 
Table 10: Correlation of PSMAs with survival outcomes in melanoma patients

\begin{tabular}{ccccccccc}
\hline Gene & $\begin{array}{c}\text { Affymetrix } \\
\text { ID }\end{array}$ & Dataset & Cancer type & $\begin{array}{c}\text { Survival } \\
\text { outcome }\end{array}$ & $\begin{array}{c}\text { No. of } \\
\text { cases }\end{array}$ & HR & $\mathbf{9 5 \%}$ CI & p-value \\
\hline PSMA1 & 211746_x_at & GSE22138 & Uveal melanoma & DMFS & 63 & 1.58 & $0.96-2.62$ & 0.074 \\
& & GSE19234 & Skin melanoma & OS & 38 & 18.53 & $2.68-128.33$ & $\mathbf{0 . 0 0 3}$ \\
PSMA2 & 201316_at & GSE22138 & Uveal melanoma & DMFS & 63 & 1.14 & $0.75-1.74$ & 0.526 \\
& & GSE19234 & Skin melanoma & OS & 38 & 1.99 & $0.72-5.50$ & 0.182 \\
PSMA3 & 201532_at & GSE22138 & Uveal melanoma & DMFS & 63 & 1.55 & $1.06-2.28$ & $\mathbf{0 . 0 2 4}$ \\
& & GSE19234 & Skin melanoma & OS & 38 & 1.10 & $0.23-5.30$ & 0.907 \\
PSMA4 & 203396_at & GSE22138 & Uveal melanoma & DMFS & 63 & 1.18 & $0.89-1.55$ & 0.246 \\
& & GSE19234 & Skin melanoma & OS & 38 & 3.48 & $0.58-20.81$ & 0.172 \\
PSMA5 & 230300_at & Not available & & & & & & \\
PSMA6 & 208805_at & GSE22138 & Uveal melanoma & DMFS & 63 & 1.53 & $0.90-2.62$ & 0.119 \\
& & GSE19234 & Skin melanoma & OS & 38 & 2.04 & $0.31-13.33$ & 0.459 \\
PSMA7 & 201114_x_at & GSE22138 & Uveal melanoma & DMFS & 63 & 4.53 & $1.74-11.76$ & $\mathbf{0 . 0 0 2}$ \\
& & GSE19234 & Skin melanoma & OS & 38 & 9.44 & $1.77-50.33$ & $\mathbf{0 . 0 0 9}$ \\
\hline
\end{tabular}

HR: hazard ratio; CI: confidence interval; OS: overall survival; DMFS: distant metastasis free survival.

in p21-HBx transgenic mice [57]. Combined with higher proteasome activity, increased levels of PSMA5 and PSMAD4 could be detected in colorectal cancer [55]. In this study, we systematically analyzed the mRNA expression levels of PSMA1-7 in multiple human cancers based on Oncomine and TCGA databases. The results showed that the mRNA expression levels of all seven PSMAs were significantly upregulated in breast, lung, gastric, bladder and head and neck cancer compared with normal tissues. In colorectal cancer, PSMA1-5 and PSMA7 were demonstrated to be overexpressed in tumor tissues. Notably, although PSMA1-4 and PSMA6-7 were increased in overall kidney cancer, the transcriptional patterns of PSMAs were different among the three subtypes. For instance, the mRNA expression level of PSMA3 was elevated in kidney chromophobe cell carcinoma, but not in clear cell or papillary cell carcinoma. Moreover, we also revealed that melanoma had higher levels of PSMA1 and PSMA3-6 compared with normal tissues.

It has been reported that many proteasome subunits are significantly associated with various clinicopathological features and survival outcomes for cancer patients. In ovarian cancer, high expression of PSMB4 was closely related to tumor grade, tumor stage, lymph node, ascites and Ki-67, as well as worse OS [11]. Hepatocellular cancer patients with higher expression of PSMD10 were found to be characterized by increased tumor size, vascular invasion as well as intrahepatic or distant metastasis and would suffer a poor OS or shorter DFS than low-expression patients [9]. Langlands et al. demonstrated that positive expression of PSMD9 was significantly correlated with higher rates of local recurrence after radiotherapy in breast cancer [58]. Another study reported that overexpression of PSMD2 predicted a poor prognosis for lung adenocarcinoma patients [7].

Nevertheless, as for the PSMAs, only a limited number of studies have investigated the prognostic significance in human cancers. One clue provided by a previous study showed that overexpression of PSMA7 in protein level was significantly associated with liver metastasis and worse prognosis in colorectal cancer [10]. Hence, it is reasonable to speculate that the mRNA expression of certain PSMAs might correlate with survival outcomes for cancer patients. In the present study, we found that high expression of PSMA1-4 and PSMA6-7 was significantly associated with worse prognosis in breast cancer, while PSMA5 was related to better OS, RFS and DMFS. Moreover, we also observed that these significant correlations were specifically present in the luminal A and B subtypes of breast cancer. In lung cancer, PSMA1-2, PSMA4 and PSMA5 were correlated with better prognosis, whereas PSMA6 and PSMA7 predicted worse survival outcomes. However, such correlations might only be applicable to lung adenocarcinoma but not squamous cell carcinoma. Intriguingly, all seven genes were significantly associated with better prognosis for overall gastric cancer and HER2-negative gastric cancer. In ovarian cancer, only PSMA1 was marginally correlated with PPS. Although significant association between certain PSMAs and clinical outcomes was observed in colorectal cancer and melanoma, caution should be taken due to the limited number of cases. Regretfully, survival data for bladder, kidney and head and neck cancer were not available in the KM Plotter or PrognScan databases. 
Table 11: Analyses of PMSAs in head and neck cancer

\begin{tabular}{|c|c|c|c|c|c|c|}
\hline Gene & Dataset & Normal (Cases) & Tumor (Cases) & $\begin{array}{c}\text { Fold } \\
\text { change }\end{array}$ & $t$-Test & $p$-value \\
\hline \multirow[t]{3}{*}{ PSMA1 } & Pyeon Multi-cancer & Cervix Uteri (8)/Oral Cavity (9)/Palate (1)/Tonsil (4) & Oropharyngeal Carcinoma (6) & 2.701 & 5.992 & 4.34E-06 \\
\hline & & Cervix Uteri (8)/Oral Cavity (9)/Palate (1)/Tonsil (4) & Floor of the Mouth Carcinoma (5) & 3.025 & 5.833 & $5.00 \mathrm{E}-05$ \\
\hline & & Cervix Uteri (8)/Oral Cavity (9)/Palate (1)/Tonsil (4) & Tongue Carcinoma (15) & 2.106 & 4.358 & $5.61 \mathrm{E}-05$ \\
\hline \multirow[t]{5}{*}{ PSMA2 } & Pyeon Multi-cancer & Cervix Uteri (8)/Oral Cavity (9)/Palate (1)/Tonsil (4) & Oropharyngeal Carcinoma (6) & 3.574 & 8.266 & $6.05 \mathrm{E}-09$ \\
\hline & & Cervix Uteri (8)/Oral Cavity (9)/Palate (1)/Tonsil (4) & Tongue Carcinoma (15) & 3.107 & 6.079 & $3.04 \mathrm{E}-07$ \\
\hline & & Cervix Uteri (8)/Oral Cavity (9)/Palate (1)/Tonsil (4) & Floor of the Mouth Carcinoma (5) & 3.803 & 7.187 & $6.12 \mathrm{E}-07$ \\
\hline & & Cervix Uteri (8)/Oral Cavity (9)/Palate (1)/Tonsil (4) & Tonsillar Carcinoma (6) & 2.227 & 4.070 & $3.69 \mathrm{E}-04$ \\
\hline & & Cervix Uteri (8)/Oral Cavity (9)/Palate (1)/Tonsil (4) & Oral Cavity Carcinoma (4) & 3.049 & 4.748 & $9.08 \mathrm{E}-04$ \\
\hline \multirow[t]{5}{*}{ PSMA3 } & Pyeon Multi-cancer & Cervix Uteri (8)/Oral Cavity (9)/Palate (1)/Tonsil (4) & Oropharyngeal Carcinoma (6) & 4.452 & 5.399 & $1.41 \mathrm{E}-05$ \\
\hline & & Cervix Uteri (8)/Oral Cavity (9)/Palate (1)/Tonsil (4) & Oral Cavity Carcinoma (4) & 4.449 & 5.255 & $8.79 \mathrm{E}-05$ \\
\hline & & Cervix Uteri (8)/Oral Cavity (9)/Palate (1)/Tonsil (4) & Tongue Carcinoma (15) & 3.773 & 5.050 & $7.08 \mathrm{E}-06$ \\
\hline & & Cervix Uteri (8)/Oral Cavity (9)/Palate (1)/Tonsil (4) & Floor of the Mouth Carcinoma (5) & 5.384 & 5.462 & $6.19 \mathrm{E}-05$ \\
\hline & & Cervix Uteri (8)/Oral Cavity (9)/Palate (1)/Tonsil (4) & Tonsillar Carcinoma (6) & 2.060 & 2.685 & $7.00 \mathrm{E}-03$ \\
\hline \multirow[t]{8}{*}{ PSMA4 } & FriersonHF Salivary-gland & Salivary Gland (6) & Salivary Gland Adenoid Cystic Carcinoma (16) & 2.887 & 6.997 & $7.82 \mathrm{E}-07$ \\
\hline & Pyeon Multi-cancer & Cervix Uteri (8)/Oral Cavity (9)/ Palate (1)/Tonsil (4) & Oropharyngeal Carcinoma (6) & 3.181 & 6.897 & $1.17 \mathrm{E}-05$ \\
\hline & & Cervix Uteri (8)/Oral Cavity (9)/Palate (1)/Tonsil (4) & Oral Cavity Carcinoma (4) & 2.549 & 6.087 & $1.22 \mathrm{E}-04$ \\
\hline & & Cervix Uteri (8)/Oral Cavity (9)/Palate (1)/Tonsil (4) & Tongue Carcinoma (15) & 2.225 & 5.311 & 4.13E-06 \\
\hline & & Cervix Uteri (8)/Oral Cavity (9)/Palate (1)/Tonsil (4) & Floor of the Mouth Carcinoma (5) & 2.208 & 5.473 & $5.89 \mathrm{E}-05$ \\
\hline & Talbot Lung & Lung (2)/Tongue (26) & Tongue Squamous Cell Carcinoma (31) & 2.120 & 7.290 & $1.38 \mathrm{E}-09$ \\
\hline & Cromer Head-Neck & Uvula (4) & Head and Neck Squamous Cell Carcinoma (34) & 2.059 & 4.616 & $7.90 \mathrm{E}-04$ \\
\hline & Estilo Head-Neck & Tongue (26) & Tongue Squamous Cell Carcinoma (31) & 2.107 & 6.810 & $1.42 \mathrm{E}-08$ \\
\hline \multirow[t]{5}{*}{ PSMA5 } & Pyeon Multi-cancer & Cervix Uteri (8)/Oral Cavity (9)/Palate (1)/Tonsil (4) & Oropharyngeal Carcinoma (6) & 3.032 & 7.548 & $2.44 \mathrm{E}-07$ \\
\hline & & Cervix Uteri (8)/Oral Cavity (9)/Palate (1)/Tonsil (4) & Tongue Carcinoma (15) & 2.523 & 5.569 & $2.03 \mathrm{E}-06$ \\
\hline & & Cervix Uteri (8)/Oral Cavity (9)/Palate (1)/Tonsil (4) & Floor of the Mouth Carcinoma (5) & 2.697 & 6.255 & $1.72 \mathrm{E}-05$ \\
\hline & & Cervix Uteri (8)/Oral Cavity (9)/Palate (1)/Tonsil (4) & Oral Cavity Carcinoma (4) & 2.540 & 5.068 & 7.64E-04 \\
\hline & Ginos Head-Neck & Buccal Mucosa (13) & Head and Neck Squamous Cell Carcinoma (41) & 2.195 & 11.995 & $5.42 \mathrm{E}-15$ \\
\hline \multirow[t]{3}{*}{ PSMA6 } & Pyeon Multi-cancer & Cervix Uteri (8)/Oral Cavity (9)/Palate (1)/Tonsil (4) & Tongue Carcinoma (15) & 2.275 & 6.267 & $1.85 \mathrm{E}-07$ \\
\hline & & Cervix Uteri (8)/Oral Cavity (9)/Palate (1)/Tonsil (4) & Oral Cavity Carcinoma (4) & 2.388 & 5.998 & $1.15 \mathrm{E}-04$ \\
\hline & & Cervix Uteri (8)/Oral Cavity (9)/Palate (1)/Tonsil (4) & Oropharyngeal Carcinoma (6) & 2.503 & 5.214 & $2.16 \mathrm{E}-04$ \\
\hline \multirow[t]{5}{*}{ PSMA7 } & Pyeon Multi-cancer & Cervix Uteri (8)/Oral Cavity (9)/Palate (1)/Tonsil (4) & Tongue Carcinoma (15) & 2.660 & 7.577 & $3.60 \mathrm{E}-09$ \\
\hline & & Cervix Uteri (8)/Oral Cavity (9)/Palate (1)/Tonsil (4) & Oral Cavity Carcinoma (4) & 2.937 & 8.314 & $2.14 \mathrm{E}-07$ \\
\hline & & Cervix Uteri (8)/Oral Cavity (9)/Palate (1)/Tonsil (4) & Tonsillar Carcinoma (6) & 2.028 & 5.090 & $3.74 \mathrm{E}-05$ \\
\hline & & Cervix Uteri (8)/Oral Cavity (9)/Palate (1)/Tonsil (4) & Oropharyngeal Carcinoma (6) & 2.335 & 5.610 & $2.67 \mathrm{E}-05$ \\
\hline & & Cervix Uteri (8)/Oral Cavity (9)/Palate (1)/Tonsil (4) & Floor of the Mouth Carcinoma (5) & 2.540 & 6.119 & $2.69 \mathrm{E}-05$ \\
\hline
\end{tabular}

As important components of the proteasome, accumulating evidence indicates that proteasome subunits could exert different biological functions in a proteasomedependent or independent manner. For example, the most well studied subunit of proteasome, PSMD10, not only performs a proteolytic role in the degradation of multiple proteins, but also plays a non-proteolytic role in transcriptional regulation, protein trafficking and signal transducer activation [59-62]. Likewise, the PSMAs also exhibit multiple functions involved in various aspects of tumor progression. Knockdown of PSMA7 in myeloid leukemia cell K562 resulted in a marked proliferation inhibition [63]. Although PMSA7 knockdown in colorectal cancer cell line RKO showed no impact on proliferation or cell cycle, depletion of PSMA7 was demonstrated to significantly suppress tumor formation in vitro and in vivo, as well as inhibit RKO cell invasion and migration [4]. NOD1 is regulated by PSMA7 in a proteasome-dependent manner, and overexpression of PSMA7 inhibits NOD1-mediated colorectal cancer cell apoptosis [64]. The non-small cell lung cancer cell lines A549 and NCI-H460 treated with PSMA1 siRNA showed a loss of the chymotrypsinlike activity of proteasome and a significant decrease 
in homologous recombination-mediated repair of I-SceI-induced DNA double strand breaks [6]. PSMA3 participates in the ubiquitin-independent degradation of p21, which as a cyclin-dependent kinase inhibitor plays various central roles in cellular processes, by binding and recruiting p21 into proteasome for degradation $[65,66]$. Considering the widespread involvement of PSMAs in tumor processes, the potential therapeutic benefits of targeting PSMAs, as well as the limited publications regarding specially PSMA1, PSMA2, PSMA3 and PSMA5, many more studies are needed to further disclose the molecular mechanisms of PSMAs in multiple cancers.

In summary, our study systematically analyzed the mRNA expression levels and prognostic significance of PSMAs in different human cancers. These PSMAs exhibited significant expression differences between tumor and normal tissues in various types of cancer. Moreover, several PSMAs showed great prognostic significance for cancer patients. Future studies are needed to determine the detailed roles of PSMAs in tumor initiation and development, which may strengthen the evidence that PSMAs could be promising therapeutic targets and novel prognostic biomarkers for human carcinomas.

\section{MATERIALS AND METHODS}

\section{Oncomine database analysis}

Oncomine (http://www.oncomine.org), an online microarray database, was utilized to examine the mRNA expression difference of PSMAs between tumor and normal tissues in multiple human cancers. The thresholds were restricted as follows: $p$ value: 0.01 ; fold change: 2 ; gene rank: $10 \%$; data type: mRNA. For each gene, we performed comparisons by cancer vs. normal analysis. Cancer type, fold change, $t$-test value, $p$-value and sample sizes were obtained from studies that showed statistically significant differences.

\section{TCGA database analysis}

Integrin mRNA HiSeq expression data from the TCGA database involving breast cancer, lung cancer, gastric cancer, colorectal cancer and bladder cancer were downloaded from the Cancer Genomics Browser of University of California Santa Cruz (UCSC) (https:// genome-cancer.ucsc.edu/) version: 2015-02-24. Student's $t$-test was performed to investigate the mRNA expression differences between tumor and normal tissues. The boxplots were created by GraphPad software.

\section{KM Plotter database analysis}

We used KM Plotter (http://kmplot.com/analysis/) [67, 68], which contains 4142 breast, 2437 lung, 1648 ovarian and 1065 gastric cancer patients with survival data, to determine the prognostic values of PSMAs in the above four cancers. KM Plotter includs only the Affymetrix HG-U133A, HG-U133 Plus 2.0 and HG-U133A 2.0 microarrays. For each gene symbol, the desired probe ID was identified according to the file of probe sets provided by KM Plotter. Cancer patients were divided into high and low expression group by the median values of mRNA expression, and survival analyses were carried out without follow-up restrictions. Briefly, the desired probe IDs representing the seven genes were separately entered into the database to obtain Kaplan-Meier plots. Number of cases, median values of mRNA expression levels, HRs, 95\% CIs and $p$-values were extracted from the KM plotter webpage.

\section{PrognScan database analysis}

For the other kinds of cancers, PrognScan (http:// www.abren.net/PrognoScan/) [69], a large database including publicly available microarray datasets with gene expression and survival data for several cancers, was applied to evaluate the prognostic effects of PSMAs. The microarrays and probe IDs selected for each gene were in line with those used in the KM plotter database. The results of the survival analyses were downloaded from PrognScan database.

\section{ACKNOWLEDGMENTS AND FUNDING}

This study was supported by National Natural Science Foundation of China (NO. 81472475 and NO. 81102007), and Scientific Research Foundation of Chongqing Medical University (NO. 201408).

\section{CONFLICTS OF INTEREST}

The authors declare no conflicts of interest.

\section{REFERENCES}

1. Torre LA, Bray F, Siegel RL, Ferlay J, Lortet-Tieulent J, Jemal A. Global cancer statistics, 2012. CA Cancer J Clin. 2015; 65:87-108.

2. Siegel RL, Miller KD, Jemal A. Cancer statistics, 2016. CA Cancer J Clin. 2016;66: 7-30.

3. Kish-Trier E, Hill CP. Structural biology of the proteasome. Annu Rev Biophys. 2013; 42:29-49.

4. Hu XT, Chen W, Zhang FB, Shi QL, Hu JB, Geng SM, He C. Depletion of the proteasome subunit PSMA7 inhibits colorectal cancer cell tumorigenicity and migration. Oncol Rep. 2009; 22:1247-1252.

5. Mairinger FD, Walter RF, Theegarten $\mathrm{D}$, Hager $\mathrm{T}$, Vollbrecht C, Christoph DC, Worm K, Ting S, Werner R, Stamatis G, Mairinger T, Baba H, Zarogoulidis K, et al. Gene Expression Analysis of the 26S Proteasome Subunit PSMB4 Reveals Significant Upregulation, Different 
Expression and Association with Proliferation in Human Pulmonary Neuroendocrine Tumours. J Cancer. 2014; 5:646-654.

6. Cron KR, Zhu K, Kushwaha DS, Hsieh G, Merzon D, Rameseder J, Chen CC, D'Andrea AD, Kozono D. Proteasome inhibitors block DNA repair and radiosensitize non-small cell lung cancer. PLoS One. 2013; 8:e73710.

7. Matsuyama Y, Suzuki M, Arima C, Huang QM, Tomida S, Takeuchi T, Sugiyama R, Itoh Y, Yatabe Y, Goto H, Takahashi T. Proteasomal non-catalytic subunit PSMD2 as a potential therapeutic target in association with various clinicopathologic features in lung adenocarcinomas. Mol Carcinog. 2011; 50:301-309.

8. Deng S, Zhou H, Xiong R, Lu Y, Yan D, Xing T, Dong L, Tang E, Yang H. Over-expression of genes and proteins of ubiquitin specific peptidases (USPs) and proteasome subunits (PSs) in breast cancer tissue observed by the methods of RFDD-PCR and proteomics. Breast Cancer Res Treat. 2007; 104:21-30.

9. Fu J, Chen Y, Cao J, Luo T, Qian YW, Yang W, Ren YB, Su B, Cao GW, Yang Y, Yan YQ, Shen F, Wu MC, et al. p28GANK overexpression accelerates hepatocellular carcinoma invasiveness and metastasis via phosphoinositol 3-kinase/AKT/hypoxia-inducible factor-1alpha pathways. Hepatology. 2011; 53:181-192.

10. Hu XT, Chen W, Wang D, Shi QL, Zhang FB, Liao YQ, Jin M, $\mathrm{He}$ C. The proteasome subunit PSMA7 located on the $20 \mathrm{q} 13$ amplicon is overexpressed and associated with liver metastasis in colorectal cancer. Oncol Rep. 2008; 19:441-446.

11. Liu R, Lu S, Deng Y, Yang S, He S, Cai J, Qiang F, Chen C, Zhang W, Zhao S. PSMB4 expression associates with epithelial ovarian cancer growth and poor prognosis. Archives of Gynecology. 2016; 293:1-11.

12. Higashitsuji H, Higashitsuji H, Itoh $\mathrm{K}$, Sakurai T, Nagao T, Sumitomo Y, Masuda T, Dawson S, Shimada Y, Mayer RJ, Fujita J. The oncoprotein gankyrin binds to MDM2/HDM2, enhancing ubiquitylation and degradation of p53. Cancer Cell. 2005; 8:75-87.

13. Higashitsuji H, Itoh K, Nagao T, Dawson S, Nonoguchi K, Kido T, Mayer RJ, Arii S, Fujita J. Reduced stability of retinoblastoma protein by gankyrin, an oncogenic ankyrinrepeat protein overexpressed in hepatomas. Nat Med. 2000; 6:96-99.

14. Coux O, Tanaka K, Goldberg AL. Structure and functions of the 20S and 26S proteasomes. Annu Rev Biochem. 1996; 65:801-847.

15. Wang T, Chen T, Thakur A, Liang Y, Gao L, Zhang S, Tian Y, Jin T, Liu JJ, Chen M. Association of PSMA4 polymorphisms with lung cancer susceptibility and response to cisplatin-based chemotherapy in a Chinese Han population. Clin Transl Oncol. 2015; 17:564-569.

16. Liu Y, Liu P, Wen W, James MA, Wang Y, Bailey-Wilson JE, Amos CI, Pinney SM, Yang P, de Andrade M, Petersen GM, Wiest JS, Fain PR, et al. Haplotype and cell proliferation analyses of candidate lung cancer susceptibility genes on chromosome 15q24-25.1. Cancer Res. 2009; 69:7844-7850.

17. Zhang Z, Torii N, Furusaka A, Malayaman N, Hu Z, Liang TJ. Structural and functional characterization of interaction between hepatitis $\mathrm{B}$ virus $\mathrm{X}$ protein and the proteasome complex. J Biol Chem. 2000; 275:15157-15165.

18. Huang J, Kwong J, Sun EC, Liang TJ. Proteasome complex as a potential cellular target of hepatitis B virus $\mathrm{X}$ protein. $\mathrm{J}$ Virol. 1996; 70:5582-5591.

19. Hu XT, Chen W, Wang D, Shi QL, Zhang FB, Liao YQ, Jin M, He C. [High expression of proteasome subunit PSMA7 in colorectal cancer is significantly correlated with liver metastasis]. Zhonghua Zhong Liu Za Zhi. 2008; 30:515-518.

20. Radvanyi L, Singh-Sandhu D, Gallichan S, Lovitt C, Pedyczak A, Mallo G, Gish K, Kwok K, Hanna W, Zubovits J, Armes J, Venter D, Hakimi J, et al. The gene associated with trichorhinophalangeal syndrome in humans is overexpressed in breast cancer. Proc Natl Acad Sci USA. 2005; 102:11005-11010.

21. Zhao H, Langerod A, Ji Y, Nowels KW, Nesland JM, Tibshirani R, Bukholm IK, Karesen R, Botstein D, Borresen-Dale AL, Jeffrey SS. Different gene expression patterns in invasive lobular and ductal carcinomas of the breast. Mol Biol Cell. 2004; 15:2523-2536.

22. Finak G, Bertos N, Pepin F, Sadekova S, Souleimanova M, Zhao H, Chen H, Omeroglu G, Meterissian S, Omeroglu A, Hallett M, Park M. Stromal gene expression predicts clinical outcome in breast cancer. Nat Med. 2008; 14:518-527.

23. Perou CM, Sorlie T, Eisen MB, van de Rijn M, Jeffrey SS, Rees CA, Pollack JR, Ross DT, Johnsen H, Akslen LA, Fluge O, Pergamenschikov A, Williams C, et al. Molecular portraits of human breast tumours. Nature. 2000; 406:747-752.

24. Curtis C, Shah SP, Chin SF, Turashvili G, Rueda OM, Dunning MJ, Speed D, Lynch AG, Samarajiwa S, Yuan Y, Graf S, Ha G, Haffari G, et al. The genomic and transcriptomic architecture of 2,000 breast tumours reveals novel subgroups. Nature. 2012; 486:346-352.

25. Sorlie T, Perou CM, Tibshirani R, Aas T, Geisler S, Johnsen H, Hastie T, Eisen MB, van de Rijn M, Jeffrey SS, Thorsen T, Quist H, Matese JC, et al. Gene expression patterns of breast carcinomas distinguish tumor subclasses with clinical implications. Proc Natl Acad Sci USA. 2001; 98:10869-10874.

26. Sorlie T, Tibshirani R, Parker J, Hastie T, Marron JS, Nobel A, Deng S, Johnsen H, Pesich R, Geisler S, Demeter J, Perou CM, Lonning PE, et al. Repeated observation of breast tumor subtypes in independent gene expression data sets. Proc Natl Acad Sci USA. 2003; 100:8418-8423.

27. Richardson AL, Wang ZC, De Nicolo A, Lu X, Brown M, Miron A, Liao X, Iglehart JD, Livingston DM, Ganesan S. $\mathrm{X}$ chromosomal abnormalities in basal-like human breast cancer. Cancer Cell. 2006; 9:121-132.

28. Braunstein LZ, Taghian AG. Molecular Phenotype, Multigene Assays, and the Locoregional Management of 
Breast Cancer. Seminars in Radiation Oncology. 2015; 26:9-16.

29. Bhattacharjee A, Richards WG, Staunton J, Li C, Monti S, Vasa P, Ladd C, Beheshti J, Bueno R, Gillette M, Loda M, Weber G, Mark EJ, et al. Classification of human lung carcinomas by mRNA expression profiling reveals distinct adenocarcinoma subclasses. Proc Natl Acad Sci U S A. 2001; 98:13790-13795.

30. Yamagata N, Shyr Y, Yanagisawa K, Edgerton M, Dang TP, Gonzalez A, Nadaf S, Larsen P, Roberts JR, Nesbitt JC, Jensen R, Levy S, Moore JH, et al. A training-testing approach to the molecular classification of resected nonsmall cell lung cancer. Clin Cancer Res. 2003; 9:4695-4704.

31. Garber ME, Troyanskaya OG, Schluens K, Petersen S, Thaesler Z, Pacyna-Gengelbach M, van de Rijn M, Rosen GD, Perou CM, Whyte RI, Altman RB, Brown PO, Botstein D, et al. Diversity of gene expression in adenocarcinoma of the lung. Proc Natl Acad Sci USA. 2001; 98:13784-13789.

32. D'Errico M, de Rinaldis E, Blasi MF, Viti V, Falchetti M, Calcagnile A, Sera F, Saieva C, Ottini L, Palli D, Palombo F, Giuliani A, Dogliotti E. Genome-wide expression profile of sporadic gastric cancers with microsatellite instability. Eur J Cancer. 2009; 45:461-469.

33. Ki DH, Jeung HC, Park CH, Kang SH, Lee GY, Lee WS, Kim NK, Chung HC, Rha SY. Whole genome analysis for liver metastasis gene signatures in colorectal cancer. Int $\mathrm{J}$ Cancer. 2007; 121:2005-2012.

34. Skrzypczak M, Goryca K, Rubel T, Paziewska A, Mikula M, Jarosz D, Pachlewski J, Oledzki J, Ostrowski J. Modeling oncogenic signaling in colon tumors by multidirectional analyses of microarray data directed for maximization of analytical reliability. PLoS One. 2010; 5.

35. Hong Y, Downey T, Eu KW, Koh PK, Cheah PY. A 'metastasis-prone' signature for early-stage mismatchrepair proficient sporadic colorectal cancer patients and its implications for possible therapeutics. Clin Exp Metastasis. 2010; 27:83-90.

36. Sabates-Bellver J, Van der Flier LG, de Palo M, Cattaneo E, Maake C, Rehrauer H, Laczko E, Kurowski MA, Bujnicki JM, Menigatti M, Luz J, Ranalli TV, Gomes V, et al. Transcriptome profile of human colorectal adenomas. Mol Cancer Res. 2007; 5:1263-1275.

37. Smith JJ, Deane NG, Wu F, Merchant NB, Zhang B, Jiang A, Lu P, Johnson JC, Schmidt C, Bailey CE, Eschrich S, Kis C, Levy S, et al. Experimentally derived metastasis gene expression profile predicts recurrence and death in patients with colon cancer. Gastroenterology. 2010; 138:958-968.

38. Dyrskjot L, Kruhoffer M, Thykjaer T, Marcussen N, Jensen JL, Moller K, Orntoft TF. Gene expression in the urinary bladder: a common carcinoma in situ gene expression signature exists disregarding histopathological classification. Cancer Res. 2004; 64:4040-4048.
39. Sanchez-Carbayo M, Socci ND, Lozano J, Saint F, CordonCardo C. Defining molecular profiles of poor outcome in patients with invasive bladder cancer using oligonucleotide microarrays. J Clin Oncol. 2006; 24:778-789.

40. Jones J, Otu H, Spentzos D, Kolia S, Inan M, Beecken WD, Fellbaum C, Gu X, Joseph M, Pantuck AJ. Gene signatures of progression and metastasis in renal cell cancer. Clinical Cancer Research. 2005; 11:5730-5739.

41. Yusenko MV, Kuiper RP, Boethe T, Ljungberg B, van Kessel AG, Kovacs G. High-resolution DNA copy number and gene expression analyses distinguish chromophobe renal cell carcinomas and renal oncocytomas. Bmc Cancer. 2009; 9:1-10.

42. Higgins JPT, Shinghal R, Gill H, Reese JH, Terris M, Cohen RJ, Fero M, Pollack JR, Rijn MVD, Brooks JD. Gene Expression Patterns in Renal Cell Carcinoma Assessed by Complementary DNA Microarray. American Journal of Pathology. 2003; 162:925-932.

43. Christopher H, Mehdi N, Daniel S, Julia C, Daniel K, Pulliam BL, Scot F, Miller JR, Allen RE, Singer MI. The gene expression signatures of melanoma progression. Proceedings of the National Academy of Sciences of the United States of America. 2005; 102:6092-6097.

44. Talantov D, Mazumder A, Yu JX, Briggs T, Jiang Y, Backus J, Atkins D, Wang Y. Novel genes associated with malignant melanoma but not benign melanocytic lesions. Clinical Cancer Research. 2005; 11:7234-7242.

45. Bogunovic D, O'Neill DW, Belitskaya-Levy I, Vacic V, Yu YL, Adams S, Darvishian F, Berman R, Shapiro R, Pavlick AC, Lonardi S, Zavadil J, Osman I, et al. Immune profile and mitotic index of metastatic melanoma lesions enhance clinical staging in predicting patient survival. Proceedings of the National Academy of Sciences. 2009; 106:20429-20434.

46. Laurent C, Valet F, Planque N, Silveri L, Maacha S, Anezo O, Hupe P, Plancher C, Reyes C, Albaud B. High PTP4A3 phosphatase expression correlates with metastatic risk in uveal melanoma patients. Cancer Research. 2011; 71:666-674.

47. Pyeon D, Newton MA, Lambert PF, den Boon JA, Sengupta S, Marsit CJ, Woodworth CD, Connor JP, Haugen TH, Smith EM, Kelsey KT, Turek LP, Ahlquist P. Fundamental differences in cell cycle deregulation in human papillomavirus-positive and human papillomavirusnegative head/neck and cervical cancers. Cancer Res. 2007; 67:4605-4619.

48. Frierson HF, Jr., El-Naggar AK, Welsh JB, Sapinoso LM, Su AI, Cheng J, Saku T, Moskaluk CA, Hampton GM. Large scale molecular analysis identifies genes with altered expression in salivary adenoid cystic carcinoma. Am J Pathol. 2002; 161:1315-1323.

49. Talbot SG, Estilo C, Maghami E, Sarkaria IS, Pham DK, P Oc, Socci ND, Ngai I, Carlson D, Ghossein R, Viale A, Park BJ, Rusch VW, et al. Gene expression profiling allows distinction between primary and metastatic 
squamous cell carcinomas in the lung. Cancer Res. 2005; 65:3063-3071.

50. Cromer A, Carles A, Millon R, Ganguli G, Chalmel F, Lemaire F, Young J, Dembele D, Thibault C, Muller D, Poch O, Abecassis J, Wasylyk B. Identification of genes associated with tumorigenesis and metastatic potential of hypopharyngeal cancer by microarray analysis. Oncogene. 2004; 23:2484-2498.

51. Estilo CL, P Oc, Talbot S, Socci ND, Carlson DL, Ghossein R, Williams T, Yonekawa Y, Ramanathan Y, Boyle JO, Kraus DH, Patel S, Shaha AR, et al. Oral tongue cancer gene expression profiling: Identification of novel potential prognosticators by oligonucleotide microarray analysis. BMC Cancer. 2009; 9:11.

52. Ginos MA, Page GP, Michalowicz BS, Patel KJ, Volker SE, Pambuccian SE, Ondrey FG, Adams GL, Gaffney PM. Identification of a gene expression signature associated with recurrent disease in squamous cell carcinoma of the head and neck. Cancer Research. 2004; 64:55-63.

53. Adams J. The development of proteasome inhibitors as anticancer drugs. Cancer Cell. 2004; 5:417-421.

54. Chen L, Madura K. Increased proteasome activity, ubiquitin-conjugating enzymes, and eEF1A translation factor detected in breast cancer tissue. Cancer Res. 2005; 65:5599-5606.

55. Arlt A, Bauer I, Schafmayer C, Tepel J, Muerkoster SS, Brosch M, Roder C, Kalthoff H, Hampe J, Moyer MP, Folsch UR, Schafer H. Increased proteasome subunit protein expression and proteasome activity in colon cancer relate to an enhanced activation of nuclear factor E2-related factor 2 (Nrf2). Oncogene. 2009; 28:3983-3996.

56. Rho JH, Qin S, Wang JY, Roehrl MH. Proteomic expression analysis of surgical human colorectal cancer tissues: upregulation of PSB7, PRDX1, and SRP9 and hypoxic adaptation in cancer. J Proteome Res. 2008; 7:2959-2972.

57. Cui F, Wang Y, Wang J, Wei K, Hu J, Liu F, Wang H, Zhao X, Zhang X, Yang X. The up-regulation of proteasome subunits and lysosomal proteases in hepatocellular carcinomas of the HBx gene knockin transgenic mice. Proteomics. 2006; 6:498-504.

58. Langlands FE, Dodwell D, Hanby AM, Horgan K, MillicanSlater RA, Speirs V, Verghese ET, Smith L, Hughes TA. PSMD9 expression predicts radiotherapy response in breast cancer. Mol Cancer. 2014; 13:73.

59. Chen Y, Li HH, Fu J, Wang XF, Ren YB, Dong LW, Tang SH, Liu SQ, Wu MC, Wang HY. Oncoprotein p28 GANK binds to RelA and retains NF-kappaB in the cytoplasm through nuclear export. Cell Res. 2007; 17:1020-1029.
60. Luo T, Fu J, Xu A, Su B, Ren Y, Li N, Zhu J, Zhao X, Dai R, Cao J, Wang B, Qin W, Jiang J, et al. PSMD10/Gankyrin Induces Autophagy to Promote Tumor Progression through Cytoplasmic Interaction with ATG7 and Nuclear Transactivation of ATG7 Expression. Autophagy. 2016; 12:1355-1371.

61. Qian YW, Chen Y, Yang W, Fu J, Cao J, Ren YB, Zhu JJ, Su B, Luo T, Zhao XF, Dai RY, Li JJ, Sun W, et al. p28(GANK) prevents degradation of Oct4 and promotes expansion of tumor-initiating cells in hepatocarcinogenesis. Gastroenterology. 2012; 142:1547-1558.e1514.

62. Zheng T, Hong X, Wang J, Pei T, Liang Y, Yin D, Song R, Song X, Lu Z, Qi S, Liu J, Sun B, Xie C, et al. Gankyrin promotes tumor growth and metastasis through activation of IL-6/STAT3 signaling in human cholangiocarcinoma. Hepatology. 2014; 59:935-946.

63. Qin T, Fan CQ, Zhu N, Shen Y, Chen MH. [Knockdown of proteasome subunit alpha7 with small interfering RNA inhibits cell proliferation of K562 cell line]. Zhongguo Yi Xue Ke Xue Yuan Xue Bao. 2013; 35:601-606.

64. Yang L, Tang Z, Zhang H, Kou W, Lu Z, Li X, Li Q, Miao Z. PSMA7 directly interacts with NOD1 and regulates its function. Cell Physiol Biochem. 2013; 31:952-959.

65. Touitou R, Richardson J, Bose S, Nakanishi M, Rivett J, Allday MJ. A degradation signal located in the C-terminus of p21WAF1/CIP1 is a binding site for the $\mathrm{C} 8$ alpha-subunit of the 20S proteasome. Embo J. 2001; 20:2367-2375.

66. Sheaff RJ, Singer JD, Swanger J, Smitherman M, Roberts JM, Clurman BE. Proteasomal turnover of p21Cip1 does not require p21Cip1 ubiquitination. Mol Cell. 2000; 5:403-410.

67. Gyorffy B, Lanczky A, Eklund AC, Denkert C, Budczies J, Li Q, Szallasi Z. An online survival analysis tool to rapidly assess the effect of 22,277 genes on breast cancer prognosis using microarray data of 1,809 patients. Breast Cancer Res Treat. 2010; 123:725-731.

68. Szász AM, Lánczky A, Nagy Á, Förster S, Hark K, Green JE, Boussioutas A, Busuttil R, Szabó A, Győrffy B. Cross-validation of survival associated biomarkers in gastric cancer using transcriptomic data of 1,065 patients. Oncotarget. 2016; 7:49322-49333. doi: 10.18632/ oncotarget. 10337.

69. Mizuno H, Kitada K, Nakai K, Sarai A. PrognoScan: a new database for meta-analysis of the prognostic value of genes. BMC Med Genomics. 2009; 2:18. 